\title{
A DSGE-VAR Model for Forecasting Key South African Macroeconomic Variables
}

\author{
March 14, 2013
}

\begin{abstract}
The paper develops a Small Open Economy New Keynesian DSGE-VAR (SOENKDSGEVAR) model of the South African economy, characterised by incomplete pass-through of exchange rate changes, external habit formation, partial indexation of domestic prices and wages to past inflation, and staggered price and wage setting. The model is estimated using Bayesian techniques on data from the period 1980Q1 to 2003Q2, and then used to forecast output, inflation and nominal short-term interest rate for one- to eight-quarters-ahead over an out-of sample horizon of 2003Q3 to 2010Q4. When the forecast performance of the SOENKDSGE-VAR model is compared with an independently estimated DSGE model, the classical VAR and six alternative BVAR models, we find that, barring the BVAR model based on the SSVS prior on both VAR coefficients and the error covariance, the SOENKDSGE-VAR model is found to perform competitively, if not, better than all the other VAR models.
\end{abstract}

JEL Classification: C11, C53, E37

Keywords: Bayesian Methods; Macroeconomic Forecasting; New Keynesian DSGE; Small Open Economy; Vector Autoregressions

Acknowledgements: We would like to thank three anonymous referees for many helpful comments. Any remaining errors are, however, solely ours. 


\section{Table of Contents}

1 Introduction $\quad 1$

2 Estimation Methodology, Model, Priors, Data and Posterior Estimates of the DSGE Mo

2.1 The Basics of the DSGE-VAR Approach . . . . . . . . . . . . . . 3

2.2 The DSGE model . . . . . . . . . . . . . . . . . . 6

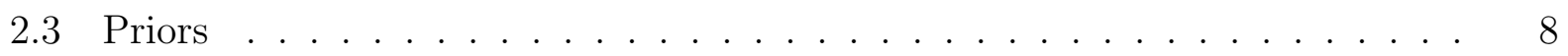

2.4 Data . . . . . . . . . . . . . . . . . . . . . 9

2.5 Posterior estimates . . . . . . . . . . . . . . . . . . . . 10

3 The Basics of the Alternative Forecasting Models $\quad 11$

3.1 The Minnesota Prior . . . . . . . . . . . . . . . . . . . . . . 12

3.2 Natural Conjugate Priors . . . . . . . . . . . . . . . . . . . 13

3.3 The Independent Normal-Wishart Prior . . . . . . . . . . . . . . . . 13

3.4 Stochastic Search Variable Selection (SSVS) Prior for VAR Coefficients . . . 15

3.5 Stochastic Search Variable Selection (SSVS) Prior for both VAR Coefficient and Error Covarianc

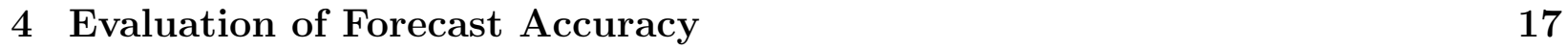

5 Conclusion $\quad 23$

$\begin{array}{ll}\text { References } & 25\end{array}$

$\begin{array}{lr}\text { Appendix } & 29\end{array}$

The full-log-linearised model . . . . . . . . . . . . . . . . . . . . . . 29 


\section{Introduction}

Recent studies, namely, Liu and Gupta (2007), Liu et al. (2009, 2010), Gupta and Kabundi (2010, forthcoming) and Alpanda et al. (2011), have initiated a growing interest in forecasting macroeconomic variables in South Africa using Dynamic Stochastic General Equilibrium (DSGE) models. ${ }^{1}$ However, in general, the studies find it difficult to outperform the atheoretical Vector Autoregressive (VAR) models, especially its Bayesian variant (BVAR) based on the Minnesota prior. These studies tend to attribute the relatively poor performance of the DSGE models to the fact that the frameworks of these models are not sophisticated enough, in the sense, that they, perhaps, do not incorporate the real and nominal rigidities to an appropriate extent to correctly capture the true dynamics of the data characterising the South African economy. ${ }^{2}$

Against this backdrop, we develop a Small Open Economy New Keynesian DSGE-VAR (hereafter SOENKDSGE-VAR) model of the South African economy, characterised by incomplete pass-through of exchange rate changes, external habit formation, partial indexation of domestic prices and wages to past inflation, and staggered price and wage setting. This model makes use of the structural framework of the theoretical DSGE to alleviate concerns relating to potential in-sample overfitting, whilst retaining the flexibility of VAR models, which often produce improved out-of-sample forecasting results. In addition, by incorporating the theoretical structure of a DSGE model, which seeks to describe the theoretical time-invariant behavior of economic agent, the SOENKDSGE-VAR model would not be subject to the Lucas critique (Lucas, 1976). ${ }^{3}$ Our decision to use a DSGE-VAR approach, over and above an independently estimated DSGE model, as done in the previous studies on South Africa, is motivated not only because of the fact that VAR models have tended to outperform DSGE model forecasts for the country, but also because of the available international evidence of DSGE-VAR models producing forecasts which are competitive, and at time substantially better, than the standard benchmark of VAR and BVAR models ${ }^{4}$.

The DSGE-VAR approach, as proposed by Del Negro and Schorfheide (2004), could be

${ }^{1}$ See also Ortiz and Sturzenegger (2007), Steinbach et al. (2009), Alpanda et al. (2010a, b) for in-sample analysis of business cycle properties of South Africa using DSGE models.

2 This line of thinking was proposed by Smets and Wouters (2007) and is vindicated to some extent by Alpanda et al. (2011), wherein the authors develop a relatively elaborate DSGE model to produce competitive forecasts in relation to VAR-type models.

3 This would be the case where it can be shown that the prior from the DSGE model influences the final results.

${ }^{4}$ See for example Del Negro and Schorfheide (2004, 2006), Del Negro et al. (2007), Hodge et al. (2008) and Lees et al. (2011). 
implemented by using a DSGE model to simulate time-series data, which is often used to populate parameter values in an unrestricted VAR model. In practice, the sample moments of the simulated data is replaced by the population moments computed from the DSGE model solution. Given that the DSGE model depends on unknown structural parameters, one uses a hierarchical prior, which involves placing a specific distribution on the DSGE models parameters. A tightness parameter $(\lambda)$, which is estimated by maximising the joint density of the data and the parameters, controls the weight of the DSGE model prior relative to the weight of the actual sample, with the values of $0, \infty$ and 1 implying an unrestricted VAR, an independently estimated DSGE model ${ }^{5}$ and a DSGE-VAR model with equal weight being given to the DSGE and the VAR. ${ }^{6}$ Finally, Markov Chain Monte Carlo (MCMC) methods are used to generate draws from the joint posterior distribution of the VAR and DSGE model parameters.

The model is estimated using Bayesian techniques on data for South Africa and the United States (US) from the period 1980Q1 to 2003Q2, and then used to forecast output, inflation and a measure of nominal short-term interest rate for one- to eight-quarters-ahead over an out-of-sample horizon of 2003Q3 to 2010Q4. With South Africa moving to a flexible exchange rate regime in 1979, the starting point of the in-sample was obvious, while, the beginning of the out-of-sample horizon is chosen to correspond with the period when the inflation rate reverted back to the inflation targeting band of 3 percent to 6 percent. In the February of 2000, the Minister of Finance, announced that the sole objective of the South African Reserve Bank (SARB) will be to achieve and maintain price stability. ${ }^{7}$ In this regard, the SARB would pursue a goal to ensure that the inflation is within the target band by the

${ }^{5}$ Note that, we do not explicitly estimate the DSGE model independently, we just use a large weight on $\lambda$ as in Del Negro et al., (2007), which is akin to estimating the DSGE model on its own.

${ }^{6}$ Intuitively, the DSGE-VAR approach starts from the assumption that a DSGE model may provide useful restrictions for the VAR parameters, in the sense that these restrictions can improve the models forecasting performance. With the DSGE models at times being overly simplified structure of the true economy, one does not want to impose these restrictions dogmatically. Instead, the DSGE model is used as prior information in the estimation. As is well known since the work of Theil and Goldberger (1961), one way to incorporate prior information into the estimation is to augment the sample with dummy observations that reflect the prior. This is precisely what is done in the DSGE-VAR estimation: First, dummy observations are simply data generated by the DSGE model, and second, the VAR parameters are estimated using both the actual and the dummy observations, with the weight on the prior determining how much of the data generate from the DSGE model is used in the estimation. The reader is referred to Del Negro and Shorfheide (2003) for further details.

7 More specifically, the SARB has now adopted an explicit inflation targeting regime, whereby it aims to keep the CPIX inflation rate, where CPIX is defined as Consumer Price Index (CPI) excluding interest rates on mortgage bonds, within the target band of 3 percent to 6 percent, using discretionary changes in the Repurchase (Repo) rate as its main policy instrument. 
end of 2002. With the target band being achieved in 2003Q2, we decided to use 2003Q3 as the starting date of our out-of-sample forecasting exercise. Note that, the endpoint of the sample is purely driven by data availability at the time this paper was written.

The forecast performance of the SOENKDSGE-VAR model is then compared with an independently estimated DSGE model, the classical VAR and BVAR models, with the latter being estimated based on six alternative priors, namely, Non-Informative and Informative Natural Conjugate priors, the Minnesota prior, Independent Normal-Wishart Prior, Stochastic Search Variable Selection (SSVS) prior on VAR coefficients and SSVS prior on both VAR coefficients and error covariance. After comparing the forecasts from the independently estimated DSGE and the DSGE-VAR models, we can determine exactly where the gains in the forecasting performance relative to standard benchmarks (if any), emanate from, i.e., whether it is because of the DSGE framework or due to estimation of the model based on the DSGE-VAR approach or both. To the best of our knowledge, this is the first attempt in forecasting key variables of the South African economy using a DSGE-VAR approach. In addition, we go beyond the convention in the forecasting literature of DSGE models, by incorporating BVAR models estimated under wider set of priors assumptions (besides the Minnesota prior).

The remainder of the paper is organised as follows: Respective subsections in Section 2 lays out the estimation methodology of the DSGE-VAR model, a discussion on the DSGE framework, data, the priors imposed on the DSGE model parameters and the estimation results. Section 3 presents the basics of the alternative forecasting models, while, Section 4 compares the performance of the DSGE-VAR model relative to an independently estimated DSGE model, the classical VAR and the BVAR under six alternative prior assumptions. Finally, Section 5 concludes.

\section{Estimation Methodology, Model, Priors, Data and Posterior Estimates of the DSGE Model}

\subsection{The Basics of the DSGE-VAR Approach}

This subsection provides a brief overview of the methodology used to estimate the DSGEVAR model, and follows closely the discussion in Del Negro and Schorfheide (2004).

Let the parameters of the DSGE model, which we describe in the next subsection, be denoted by the vector $\theta$. Let $y_{t}$ denote the column vector of $n$ observable variables, which are also 
the variables included in the VAR. That is,

$$
y_{t}=\Phi_{0}+\Phi_{1} y_{t-1}+\Phi_{2} y_{t-2}+\ldots+\Phi_{p} y_{t-p}+u_{t}
$$

where: $\Phi_{0}$ is a vector of constants; $\Phi_{1 \ldots p}$ are matrices of VAR parameters; and $u_{t} \sim N\left(0, \Sigma_{u}\right)$. This can be written more compactly as $Y=X \Phi+U$, where: $Y$ and $U$ are matrices with rows $y_{t}^{\prime}$ and $u_{t}^{\prime}$ respectively; $X$ has rows $1, y_{t-1}^{\prime}, y_{t-2}^{\prime}, \ldots, y_{t-p}^{\prime}$ and $\Phi \equiv\left[\Phi_{0}, \Phi_{1}, \Phi_{2}, \ldots, \Phi_{p}\right]^{\prime}$. It is noteworthy that the number of parameters in the DSGE model is much smaller than that in the VAR, hence the VAR tends to have a greater ability to fit the data.

As in Del Negro and Schorfheide (2004), we want to use a DSGE model to provide information about the parameters of the VAR. One way of doing this would be to simulate data from the DSGE and to combine it with the actual data and then estimate the VAR, with $\lambda$ governing the relative weight placed on the prior information, since it is a measure of the relative share of simulated observations compared to the actual data.

However, rather than simulating data, one can instead use the solution to the log-linearised version of the DSGE model to analytically compute the population moments of $y_{t}$, since the DSGE model specifies the stochastic process for $y_{t}$. So by choosing $\lambda$, we can scale these moments to be equivalent in magnitude to the (non-standardised) sample moments that would have been obtained through simulation. Given this, we can then formulate the prior for the VAR parameters, $p\left(\Phi, \Sigma_{u} \mid \theta\right)$, given $\theta$, as $\Sigma_{u} \mid \theta \sim I W$ and $\Phi \mid \Sigma_{u}, \theta \sim N$, i.e., in an Inverted-Wishart (IW)-Normal $(\mathrm{N})$ form. Note, the parameters of these prior densities are functions of the population moments calculated from the DSGE model. ${ }^{8}$ Given that, we also have prior beliefs about the parameters of the DSGE model, $p(\theta)$. The joint prior density of both sets of parameters is then given by:

$$
p\left(\Phi, \Sigma_{u}, \theta\right)=p\left(\Phi, \Sigma_{u} \mid \theta\right) p(\theta)
$$

The posterior distribution of the VAR parameters, $p\left(\Phi, \Sigma_{u} \mid Y, \theta\right)$, is obtained by the likelihood function, which is essentially the combination of the prior with information from the data. Note the likelihood, reflecting the distribution of the innovations $\left(u_{t}\right)$, and the priors for the VAR parameters conjugate, since the former is multivariate normal, while the latter is Inverted-Wishart-Normal. This is particularly helpful, since it allows the posterior to be

8 See Equations (24) and (25) in Del Negro and Schorfheide (2004) for further details. 
$\Sigma_{u} \mid \theta, Y \sim I W$ and $\Phi \mid \Sigma_{u} . \theta, Y \sim N,{ }^{9}$ i.e., the posterior follows the same class of distributions as the prior. Finally, by first drawing a $\theta$ from the posterior of the DSGE parameters and then sampling from these distributions allows us to simulate the posterior for the VAR parameters.

Note, the posterior of the VAR is conditional on a choice of $\lambda$. Let the set of possible $\lambda$ be given by $\Lambda$, where $\Lambda \equiv\left\{\lambda_{1}, \ldots, \lambda_{i}, \ldots, \lambda_{q}\right\}$, and for all $i, \lambda_{i}>0$. Del Negro and Schorfheide (2004) suggests the use of the marginal data density, $p(Y \mid \lambda),{ }^{10}$ to compare the model evaluated at each $\lambda \in \Lambda$, which, in turn, can be obtained by integrating out the parameters of the joint density of the data and the parameters as follows:

$$
\begin{aligned}
p(Y \mid \lambda) & \equiv \int_{\Sigma_{u}^{*}, \Phi^{*}, \theta^{*}} p\left(Y, \theta, \Sigma_{u}, \Phi \mid \lambda\right) d\left(\Sigma_{u}, \Phi, \theta\right) \\
& =\int_{\Sigma_{u}^{*}, \Phi^{*}, \theta^{*}} p\left(Y \mid \theta, \Sigma_{u}, \Phi\right) p\left(\theta, \Sigma_{u}, \Phi \mid \lambda\right) d\left(\Sigma_{u}, \Phi, \theta\right),
\end{aligned}
$$

where $\Sigma_{u}^{*}, \Phi^{*}$ and $\theta^{*}$ are the sets of possible parameter values for $\Sigma_{u}, \Phi$ and $\theta$ respectively. Though the integration involved in calculating the marginal data density is computationally intensive, but with $p\left(\Phi, \Sigma_{u}, \theta \mid \lambda\right)$ equals $p\left(\Phi, \Sigma_{u} \mid \theta, \lambda\right) p(\theta)$, and $p\left(\Phi, \Sigma_{u} \mid \theta\right)$ is of InvertedWishart-Normal form, the latter enables the integrals with respect to the VAR parameters to be calculated analytically. This leaves only the integral with respect to $\theta$ to be calculated in order to approximate $p(Y \mid \lambda) .{ }^{11}$ An 'optimal' $\lambda, \hat{\lambda}$, could then be obtained so as to maximise $p(Y \mid \lambda)$, that is,

$$
\hat{\lambda}=\arg \max _{\lambda \in \Lambda} p(Y \mid \lambda)
$$

Note one could also use the marginal data density to pick the lag length of the VAR, $p$ (Del Negro and Schorfheide, 2004). We, however, use the unanimity amongst the conventional lag-length tests, namely, the LR test statistic, Akaike information criterion (AIC), the final prediction error (FPE) criterion, the Schwarz information criterion (SIC), as well as the Hannan-Quinn (HQ) information criterion, to decide on our optimal lag length to be used in the VAR (Lees et al., 2011).

${ }^{9}$ We have suppressed the parameters of the posterior distributions. See Equations (30) and (31) in Del Negro and Schorfheide (2004) for further details.

${ }^{10}$ The notation of the marginal data density follows Del Negro et al (2007). Also, previously we suppressed the fact that many of the densities, like, the joint prior density for the parameters of the VAR and the DSGE models are conditional on $\lambda$.

${ }^{11}$ See Geweke (1999) and An and Schorfheide (2007). 


\subsection{The DSGE model}

The DSGE model structure builds on standard small open economy New Keynesian models (see Monacelli (2005) and Justiniano and Preston (2004)). Additional nominal rigidities are added to the staggered wage and price setting framework (Calvo, 1983) through partial indexation of domestic prices to their past inflation, as well as partial indexation of wages to past consumer price inflation. Moreover, the model structure allows for incomplete pass-through of exchange rate movements over the short run. Real rigidity emanates from external habit formation in consumption. The small open economy assumption implies that the relative size of the foreign economy, i.e. the rest of the world in the context of this model, is so large that it is not affected by developments in the South African economy and therefore approximates a closed economy. Hence, the model structure of the foreign economy is symmetric to the domestic economy, save for it being closed.

The key log-linearised equations are provided below. ${ }^{12}$

$$
\begin{aligned}
c_{t} & =\frac{1}{1+h} E_{t} c_{t+1}+\frac{h}{1+h} c_{t-1}-\frac{1-h}{\sigma(1+h)}\left[r_{t}-E_{t} \pi_{t+1}+\varepsilon_{t}^{d}\right] \\
\pi_{t}^{h} & =\frac{\omega}{1+\omega \beta} \pi_{t-1}^{h}+\frac{\beta}{1+\omega \beta} E_{t} \pi_{t+1}^{h}+\frac{\left(1-\theta_{h}\right)\left(1-\theta_{h} \beta\right)}{\theta_{h}(1+\omega \beta)} m c_{t} \\
m c_{t} & =r w_{t}-a_{t}+\gamma s_{t}+\varepsilon_{t}^{p} \\
\pi_{t}^{w} & =\alpha \pi_{t-1}+\beta E_{t} \pi_{t+1}^{w}-\alpha \beta \pi_{t}+\frac{\left(1-\theta_{w}\right)\left(1-\theta_{w} \beta\right)}{\theta_{w}\left(1+\xi_{w} \varphi\right)} \mu_{t}^{w} \\
\pi_{t}^{f} & =\beta E_{t} \pi_{t+1}^{f}+\frac{\left(1-\theta_{f}\right)\left(1-\theta_{f} \beta\right)}{\theta_{f}} \psi_{t} \\
\psi_{t} & =\psi_{t-1}+\Delta e_{t}+\pi_{t}^{*}-\pi_{t}^{f} \\
\pi_{t} & =(1-\gamma) \pi_{t}^{h}+\gamma \pi_{t}^{f} \\
r_{t} & =\rho_{r} r_{t-1}+\left(1-\rho_{r}\right)\left[\phi_{\pi} \pi_{4, t+1}+\phi_{y} y_{t}\right]+\varepsilon_{t}^{r} \\
E_{t} q_{t+1} & =q_{t}+\left(r_{t}-E_{t} \pi_{t+1}\right)-\left(r_{t}^{*}-E_{t} \pi_{t+1}^{*}\right)+\phi_{t} \\
y_{t} & =a_{t}+l_{t} \\
y_{t} & =(1-\gamma) c_{t}+\eta \gamma(2-\gamma) s_{t}+\gamma y_{t}^{*}+\eta \gamma \psi_{t} \\
y_{t}^{*} & =h y_{t-1}^{*}+\frac{\sigma}{\sigma^{*}}\left(c_{t}-h c_{t-1}\right)-\frac{1-h}{\sigma^{*}} q_{t}
\end{aligned}
$$

Eq. (5) is the consumption Euler equation. Consumption, denoted by $c_{t}$, is determined by past values of consumption, expectations about future consumption in $t+1$, and the ex ante

\footnotetext{
${ }^{12}$ Lower case letters represent log-deviations from steady state. The full log-linearised model is provided in
} Appendix A. 
real interest rate, $r_{t}-E_{t} \pi_{t+1}$. In addition, shocks to consumption emanate from the external demand shock $\varepsilon_{t}^{d}$, which is assumed to follow the $\operatorname{AR}(1)$ process $\varepsilon_{t}^{d}=\rho_{d} \varepsilon_{t-1}^{d}+\nu_{t}^{d}$, where $\nu_{t}^{d} \sim$ i.i.d $N\left(0, \sigma_{d}^{2}\right)$. The parameter $h$ in Eq. (5) represents the degree of habit formation in consumption and $\sigma$ is the inverse of the intertemporal elasticity of substitution for consumption.

Domestic inflation, denoted by $\pi_{t}^{h}$, is represented by a Phillips-curve in Eq. (6). It is modelled as a function of its own lagged values, expected domestic inflation in $t+1$ and marginal costs, $m c_{t}$. Three parameters govern the dynamics of this equation: (i) the discount factor $\beta$; (ii) the degree of indexation to past inflation $\omega$; and (iii) the degree of price stickiness reflected by the Calvo (1983) parameter $\theta_{h}$. Marginal costs are a function of real wage $\left(r w_{t}\right)$ increases in excess of productivity gains $\left(a_{t}\right)$, the terms of trade $\left(s_{t}\right)$ and a price markup shock $\left(\varepsilon_{t}^{p}\right)$. As in Smets and Wouters (2007), the price markup shock is assumed to follow an $\operatorname{ARMA}(1,1)$ process $\varepsilon_{t}^{p}=\rho_{p} \varepsilon_{t-1}^{p}+\nu_{t}^{p}+\mu_{p} \nu_{t-1}^{p}$, where $\nu_{t}^{p} \sim$ i.i.d $N\left(0, \sigma_{p}^{2}\right)$. The inclusion of the MA(1) term should capture some of the high-frequency fluctuations that are observed in actual inflation.

A Phillips-curve type relationship also holds for nominal wage inflation $\left(\pi_{t}^{w}\right)$ in Eq. (8), where wages are partially indexed to consumer price inflation, $\pi_{t}$. The wage mark-up $\left(\mu_{t}^{w}\right)$ serves as a wedge between the real wage and the marginal rate of substitution between labour and consumption, that arises due to wage stickiness. The nature of the parameters that determine the dynamics of wage inflation are similar to those of Eq. (6), as $\alpha$ captures the degree of indexation to past consumer price inflation and $\theta_{w}$ reflects degree of wage stickiness. In addition, since $\varphi$ is the inverted labour supply elasticity, $\xi_{w} \varphi$ represent the ratio of the labour demand and supply elasticities.

Eq. (9) indicates that imported inflation, denoted by $\pi_{t}^{f}$, is a function of expected imported inflation in $t+1$ and the degree of imperfect exchange rate pass-through, $\psi_{t}$. Imperfect exchange rate pass-through is reflected by deviations from the law-of-one-price in Eq. (10), where $\Delta e_{t}$ is the change in the nominal exchange rate and $\pi_{t}^{*}$ represents foreign inflation. This specification reflects the assumption that importing retailers pay the world market price in domestic currency at the dock, but face a downward sloping demand curve in the domestic economy. As a result, importing retailers are not necessarily able to fully pass on changes in the domestic currency denominated world market price to the domestic economy over the short run. Nevertheless, complete exchange rate pass-through is achieved in the long-run. 
Eq. (11) relates CPI inflation to domestic and imported inflation, where $\gamma$ is the degree of openness.

Monetary policy $\left(r_{t}\right)$ is described by a Taylor-type rule in Eq. (12), where $\rho_{r}, \phi_{\pi}$ and $\phi_{y}$ are the respective weights on policy smoothing, expected year-on-year consumer price inflation $\left(\pi_{4, t+1}\right)$ and the output gap. ${ }^{13}$ The real exchange rate $\left(q_{t}\right)$ is represented by the UIP condition in Eq. (13), where $\phi_{t}$ is a risk premium. ${ }^{14}$

Finally, productivity and labour are the only inputs in production in Eq. (14), aggregate demand in the domestic economy is expressed as Eq. (15), while the model is closed by the consumption risk sharing condition in Eq. (16).

\subsection{Priors}

The model parameters are estimated with Bayesian techniques. However, given the identification issues in DSGE models that emanate from the non-linear mapping of the structural parameter vector into the model's reduced form (see Lubik and Schorfheide (2005)), certain parameters were calibrated. A parameter was calibrated where a direct comparison between the prior and posterior distribution suggested a lack of information in the data regarding the specific parameter. The calibrated parameters are summarised in Table 1.

\section{[ Insert Table 1 here ]}

The values selected for the domestic and foreign economy's discount factor, inverse elasticity of labour supply, and the labour demand elasticity are standard in the literature. Following Smets and Wouters (2007), the degree of habit formation for both economies is set to 0.7. The calibration of the import share in the domestic economy at 0.2 follows Steinbach et al. (2009). The authors justify this calibration as a combination of the actual import penetration ratios in total South African GDP and consumption. The Taylor rule smoothing parameter in the domestic economy is set to 0.73, following Ortiz and Sturzenegger (2007), who estimate a monetary policy rule for South Africa. For the foreign economy, the Taylor

\footnotetext{
${ }^{13}$ The decision to drop the exchange rate, in either its real form or changes in the nominal value, is due to the available evidence for South Africa on the insignificant role of the variable in the interest rate rule (Ortiz and Sturzenegger, 2007; Alpanda et al., 2010).

${ }^{14}$ Alpanda et al., (2010a, b, 2011) modify this standard UIP condition to allow for a negative relationship between the country risk-premium and the expected depreciation rate, which can account for the forward premium puzzle.
} 
rule smoothing parameter is calibrated to 0.75 , while the degree of wage indexation is set to 0.5 - both being fairly common calibrations in the literature.

The prior specifications of the remaining parameters largely match those used in DSGE models estimated for small open economies. Firstly, the inverted consumption substitution elasticity is assumed to be normally distributed around 1 with a standard devation of 0.2. The prior for the elasticity of substitution between home and foreign goods follows a gamma distribution, with a mean of 1 and standard deviation of 0.2. All three Calvo parameters for the domestic economy (i.e., domestic prices, wages and import prices) are assumed to follow a beta distribution, with a mean of 0.75 and standard deviation of 0.1 . A Calvo parameter of 0.75 implies that firms reoptimise their prices once a year on average, hence reflecting the prior belief that price stickiness is fairly high in South Africa. The prior for price and wage indexation is slightly lower than on the Calvo parameters, with mean 0.5 and standard deviation 0.1. Both the Taylor rule weights on inflation and the output gap are assumed to be gamma distributed, where the inflation parameter has a prior mean of 1.5, standard deviation of 0.125 and a lower bound of 1 , while the output parameter has a mean of 0.125 and standard deviation of $0.031 .{ }^{15}$

The AR(1) persistence parameters are assumed to be beta distributed with mean 0.8 and standard deviation 0.1. The standard deviations of the shocks are assumed to follow an inverse-gamma distribution with a mean of 1 and two degrees of freedom. In addition, the priors on the parameters that govern the foreign economy generally match their domestic economy counterparts.

Finally, since we do not have a strong prior belief about the the relative weight of the DSGE model, we follow Adjemian et al. (2008) and assume that $\lambda$ follows a uniform distribution between the bounds of 0 and 10 .

\subsection{Data}

Eight observable variables are used during estimation, four each for the domestic and foreign economies. The observable domestic variables are: $\pi_{t}-$ Headline Consumer Price Index (CPI) inflation at quarterly non-annualised rates (seasonally adjusted); ${ }^{16} y_{t}$ - Real Gross

\footnotetext{
${ }^{15}$ Before being adjusted to take account of the quarterly (non-annualised) interest rate and inflation in the Taylor rule, the prior on the output weight is effectively 0.5 with mean 0.125 .

${ }^{16}$ The inflation series is constructed from three seperate series. Prior to 1997Q1, the inflation series consists of CPI inflation for all metropolitan areas, as published by Statistics South Africa (StatsSA). From 1997Q1
} 
Domestic Product at market prices (seasonally adjusted); $r_{t}$ - the Repurchase rate of the South African Reserve Bank (quarterly, non-annualised); and $m c_{t}$ - marginal costs, proxied by South African real unit labour costs. ${ }^{17}$ The data for the foreign economy are proxied by the United States. Here the observable variables are: $\pi_{t}^{*}-$ US GDP deflator (seasonally adjusted and quarterly, non-annualised); $y_{t}^{*}$ - US real GDP (seasonally adjusted); $r_{t}^{*}$ - the Federal Funds rate (quarterly, non-annualised); and $l_{t}^{*}$ - hours worked, proxied by US average hours worked per week in the nonfarm private business sector. ${ }^{18}$ Please refer to Figure 1 , for data plots of the eight variables used as observable in the estimation process.

[ Insert Figure 1 here ]

\subsection{Posterior estimates}

The posterior parameter estimates - represented by the mean values of each parameter's estimated posterior distribution - are presented in Table 2. These estimates are for the full sample (i.e. 1980Q1 to 2010Q4). With respect to the domestic economy's estimates, the inverted consumption substitution elasticity is similar to the estimates of Justiniano and Preston (2010) for Australia and New Zealand. The degree of substitution between domestic and foreign goods is low, when compared to Chari, Kehoe and McGratten's (2002) calibration of 1.5. The posterior estimates of the Calvo parameters indicate that domestic prices are reoptimised slightly more frequently than imported prices. In addition, domestic price indexation is lower than anticipated. Nominal wages, being optimised once every four quarters and indexed to past CPI inflation to a high degree, reflect the wage formation process in South Africa. The Taylor rule parameter for inflation is lower than prior expectations, whereas the weight on output is higher than anticipated - perhaps reflecting the fairly pragmatic approach of the South African Reserve Bank in the setting of the policy interest rate in response to inflation, whilst also taking cognisance of developments in output. All the persistence parameters are fairly high - in line with prior expectations. In terms of the standard deviations of the shock processes, price markup shocks dominate in terms of magnitude.

to 2008Q4, CPIX (i.e. CPI excluding mortgage and interest payments) for all metropolitan and urban areas is used, and from 2009Q1 to 2010Q4, the headline CPI for all urban areas is used.

${ }^{17}$ Real unit labour costs are calculated as the ratio of real remuneration of employees to real GDP, where remuneration is deflated by the GDP deflator.

${ }^{18}$ In order to match the log-linearised model specification, all series were detrended prior to estimation. Appendix B lists the various data sources for the observed variables. Note that, unavailability of hours worked data for South Africa led us to use the real unit labour cost data as a measure of the marginal costs. 
[ Insert Table 2 here ]

For the foreign economy, the inverted consumption substitution elasticity estimate of around 1.15 is slightly lower than Smets and Wouters (2007), as they estimate this parameter at 1.38 for the US economy. When comparing the parameters that govern pricing behaviour to their domestic economy counterparts, it seems that prices and wages are reoptimised more frequently in the foreign economy, whereas price indexation is higher. While the output parameter in the Taylor rule is almost half of the magnitude of its domestic counterpart, the parameter on inflation is substantially higher for the foreign economy. However, a direct comparison of the inflation parameter in the Taylor rule to its domestic counterpart is complicated by the fact that inflation in the foreign economy is proxied by the GDP deflator, as opposed to CPI inflation in the domestic economy. As with the domestic economy, the persistence parameters that govern the $\mathrm{AR}(1)$ shock processes in the foreign economy are all high, as anticipated. In addition, the standard deviation of price markup shocks also dominated in terms of magnitude.

The posterior mode of the relative weight of the DSGE model in the SOENKDSGE-VAR, namely, $\hat{\lambda}$, is less than 1 , indicating that the data puts a larger weight on the VAR than the DSGE. ${ }^{19}$ Interestingly, this value is comparable to that obtained by Del Negro and Schorfheide (2004) for the US economy and Del Negro et al., (2007) for the Euro area, but is way smaller than those obtained for small open economies like Australia and New Zealand by Hodge et al. (2008) and Lees et al., (2011) respectively.

\section{The Basics of the Alternative Forecasting Models}

In this section, we briefly lay out the alternative Bayesian priors imposed on the VAR model, described in Eq. (1). ${ }^{20}$ Note the VAR model generally uses equal lag length for all the variables of the model. One drawback of VAR models is that many parameters need to be estimated, some of which may be insignificant. This problem of overparameterisation resulting in multicollinearity and a loss of degrees of freedom - leads to inefficient estimates and possibly large out-of-sample forecasting errors. Given this, one solution often adapted is to impose Bayesian shrinkage on lags of the dependant variables.

\footnotetext{
${ }^{19}$ Note, the posterior of $\hat{\lambda}$ for the in-sample, 1980Q1 to 2003Q2, was estimated to be 0.702 .

${ }^{20}$ This section relies heavily on the discussions available in Koop and Korobilis (2010) and Jochmann et al. (2010).
} 


\subsection{The Minnesota Prior}

Given that the early work with Bayesian VARs was carried out by researchers at the University of Minnesota or the Federal Reserve Bank of Minneapolis (see Doan et al., 1984, and Litterman, 1986), the prior, discussed below, is popularly called the Minnesota prior. We start off by rewriting: $Y=X \Phi+U$ as $y=\left(I_{n} \otimes X\right) \alpha+\varepsilon$, where $\varepsilon \sim N\left(0, \Sigma \otimes I_{n}\right)$ and $\alpha=\operatorname{vec}(\Phi)$. The Minnesota prior is based on approximations to simplify the specification of the priors and the computation. The approximation involves replacing $\Sigma$ with an estimate $\hat{\Sigma}$, with $\Sigma$ assumed to be a diagonal matrix. Given this, each equation of the VAR can be estimated independently, and we can set $\hat{\sigma_{i i}}=s_{i}^{2}$ (where $s_{i}^{2}$ is the standard OLS estimate of the error variance in the $i^{\text {th }}$ equation and $\hat{\sigma}_{i i} i i^{\text {th }}$ element of $\left.\hat{\Sigma}\right)$. After replacing $\Sigma$ with $\hat{\Sigma}$, we need to only worry about a prior for $\alpha$, which is assumed to be as follows:

$$
\alpha \sim N\left(\underline{\alpha}_{M i n}, \underline{V}_{\text {Min }}\right) .
$$

For the prior mean, $\underline{\alpha}_{\text {Min }}$, when using data in levels, $\underline{\alpha}_{\text {Min }}=0_{K n}, K=(1+n \times p)$, except for the elements corresponding to the first own lag of the dependent variable in each equation, which, in turn, is chosen to be one. When using growth rates data or detrended variables (as in our case): $\underline{\alpha}_{M i n}=0_{K n}$. The Minnesota prior assumes the prior covariance matrix, $\underline{V}_{\text {Min }}$, is diagonal. Defining $\underline{V}_{i}$ as the block of $\underline{V}_{\text {Min }}$ associated with the $K$ coefficients in equation $i$ and $\underline{V}_{i, j j}$ to be its diagonal elements, then traditionally the Minnesota prior would be set as follows:

$$
\underline{V}_{i, j j}= \begin{cases}\frac{\underline{a}_{1}}{r^{2}} & \text { for coefficients on own lag } r \text { for } r=1, \ldots . p . \\ \underline{\underline{a}}_{2} \sigma_{i i} & \text { for coefficients on lag } r \text { of variable } j \neq i \text { for } r=1, \ldots . p \\ r^{2} \sigma_{j j} & \text { for coefficients on exogenous variables }\end{cases}
$$

The form of $\underline{V}_{i, j j}$ imposes the fact that, coefficients on longer lags shrink to zero by choosing $\underline{a}_{1}>\underline{a}_{2}$, with own lags being more important predictors than lags of other variables. The exact choice of values for $\underline{a}_{1}, \underline{a}_{2}$ and $\underline{a}_{3}$ depends on the empirical application in concern. For instance, in our case, we experimented with a wide number of values for $\underline{a}_{1}, \underline{a}_{2}$ and $\underline{a}_{3}$ to ensure that we obtain the best forecasts for the three key macro variables. ${ }^{21}$ Finally, the researcher generally sets: $\sigma_{i i}=s_{i}^{2}$.

${ }^{21}$ Following Koop and Korobilis (2010), we set: $\underline{a}_{1}=2, \underline{a}_{2}=2$, and $\underline{a}_{3}=100$. 


\subsection{Natural Conjugate Priors}

Given the VAR described above, the natural conjugate prior has the following form:

$$
\alpha \mid \Sigma \sim N(\underline{\alpha}, \Sigma \otimes \underline{V})
$$

and

$$
\Sigma^{-1} \sim W\left(\underline{S}^{-1}, \underline{v}\right) .
$$

where $\underline{\alpha}, \underline{V}, \underline{v}$ and $\underline{S}$ are prior hyperparameters that need to be chosen by the researcher. The noninformative prior requires one to set $\underline{v}=\underline{S}=\underline{V}^{-1}=c I$ and letting $c \rightarrow 0$. Note, the major drawback of the non-informative prior is that it does not impose any shrinkage. ${ }^{22}$

\subsection{The Independent Normal-Wishart Prior}

Note that the natural conjugate prior imposes $\alpha \mid \Sigma$ to be Normal and $\Sigma^{-1}$ to be Wishart. In this set up, $\alpha$ and $\Sigma$ are not independent of one another, since the prior for $\alpha$ depends on $\Sigma$. Given this, we now lay out a prior which imposes VAR coefficients and the error covariance to be independent of one another, in other words, independent Normal-Wishart prior. We need to modify our notations of the VAR model to allow for different equations in the VAR to have different explanatory variables. We now use $\beta=\operatorname{vec}(\Phi)$ rather than $\alpha$, and write each equation of the VAR as:

$$
y_{m t}=z_{m t}^{\prime} \beta_{m}+\varepsilon_{m t}
$$

with $t=1, T$ observations for $m=1, n$ variables. $y_{m t}$ is the $t^{t h}$ observation on the $m^{t h}$ variable, $z_{m t}$ is a $k_{m}$-vector containing the $t^{t h}$ observation of the vector of explanatory variables relevant for the $m^{t h}$ variable, $\beta_{m}$ is an accompanying $k_{m}$-vector of regression coefficients. Here, we allow $z_{m t}$ to vary across equations, and, hence, can create a restricted VAR, whereby some of the coefficients on the lagged dependent variables can be restricted to zero.

\footnotetext{
${ }^{22}$ Classical VAR models are also subject to this critique.
} 
Stacking all equations into vectors or matrices as: $y_{t}=\left(y_{1 t}, \ldots, y_{n t}\right)^{\prime}, \varepsilon_{t}=\left(\varepsilon_{1 t}, \ldots, \varepsilon_{n t}\right)^{\prime}$ and

$$
\beta=\left(\begin{array}{c}
\beta_{1} \\
\cdot \\
\cdot \\
\cdot \\
\beta_{n}
\end{array}\right), Z_{t}=\left(\begin{array}{cccccc}
z_{1 t}^{\prime} & 0 & \cdot & \cdot & \cdot & 0 \\
0 & z_{2 t}^{\prime} & \cdot & \cdot & \cdot & \cdot \\
\cdot & & \cdot & & \cdot \\
\cdot & & & \cdot & & \cdot \\
\cdot & & & & \cdot & 0 \\
0 & . & . & \cdot & 0 & z_{n t}^{\prime}
\end{array}\right)
$$

where $\beta$ is a $k \times 1$ vector, $Z_{t}$ is $n \times k$ where $k=\sum_{j=1}^{n} k_{j}$, and $\varepsilon \sim$ i.i.d. $N(o, \Sigma)$. Then, $y_{t}=Z_{t} \beta+\varepsilon_{t}$. Further writing,

$$
y=\left(\begin{array}{c}
y_{1} \\
\cdot \\
\cdot \\
\cdot \\
y_{T}
\end{array}\right), \varepsilon=\left(\begin{array}{c}
\varepsilon_{1} \\
\cdot \\
\cdot \\
\cdot \\
\varepsilon_{T}
\end{array}\right), Z=\left(\begin{array}{c}
Z_{1} \\
\cdot \\
\cdot \\
\cdot \\
Z_{T}
\end{array}\right)
$$

We can now write:

$$
y=Z \beta+\varepsilon,
$$

with $\varepsilon \sim N(0, I \otimes \Sigma)$. Given the model above, a very general prior is the independent Normal-Wishart prior, that can be described as follows:

$$
p\left(\beta, \Sigma^{-1}\right)=p(\beta) p\left(\Sigma^{-1}\right)
$$

where

$$
\beta \sim N\left(\underline{\beta}, \underline{V}_{\beta}\right)
$$

and

$$
\Sigma^{-1} \sim W\left(\underline{S}^{-1}, \underline{v}\right)
$$

Unlike the natural conjugate prior, the independent Normal-Wishart prior leaves the prior covariance matrix, $\underline{V}_{\beta}$, to be completely at the researcher's discretion and does not restrict it to the $\Sigma \otimes \underline{V}$ form. A noninformative prior in this context would amount to setting:

$$
\underline{v}=\underline{S}=\underline{V}_{\beta}^{-1}=0 .
$$




\subsection{Stochastic Search Variable Selection (SSVS) Prior for VAR Coefficients}

The SSVS prior carries out the shrinkage in an automatic fashion, and, hence, unlike that of the Bayesian priors described above requires only minimal prior input from the researcher. The SSVS approach can take various forms, we, however, outline the implementation of George et al. (2008).

Suppose $\alpha_{j}$ is a VAR coefficient. The SSVS specifies a hierarchical prior which is a mixture of two Normal distributions as follows:

$$
\alpha_{j} \mid \gamma_{j} \sim\left(1-\gamma_{j}\right) N\left(0, \kappa_{0 j}^{2}\right)+\gamma_{j} N\left(0, \kappa_{1 j}^{2}\right)
$$

where $\gamma_{j}$ is a dummy variable taking a value of one or zero such that $\alpha_{j}$ is then drawn from the second Normal and the first Normal respectively. The SSVS aspect of this prior arises by choosing the first prior variance, $\kappa_{0 j}^{2}$, to be "small" (implying the coefficient to be virtually zero) and the second prior variance, $\kappa_{1 j}^{2}$, to be "large" (suggesting a non-informative prior for the corresponding coefficient). The SSVS prior, in some sense, is like automatically selecting a restricted VAR. Since, based on data, it can set $\gamma_{j}=0$, and, thus, delete the corresponding lagged dependent variable from the model. At each recursive estimation during a forecasting exercise, the SSVS method calculates the $\operatorname{Pr}\left(\gamma_{j}=1 \mid y\right)$, thus allowing us to forecast using the restricted VAR which includes only the coefficients for which $\operatorname{Pr}\left(\gamma_{j}=1 \mid y\right)$ exceeds a certain critical value. Note that $\operatorname{Pr}\left(\gamma_{j}=1 \mid y\right)$ can be different at different points in time in the recursive forecasting exercise.

George et al. (2008) describes a so-called "default semi-automatic approach" to selecting the prior hyperparameters $\kappa_{0 j}$ and $\kappa_{1 j}$, such that: $\kappa_{0 j}=c_{0} \sqrt{\operatorname{var}\left(\alpha_{j}\right)}$ and $\kappa_{1 j}=c_{1} \sqrt{\operatorname{var}\left(\alpha_{j}\right)}$ where $\operatorname{var}\left(\alpha_{j}\right)$ is an estimate of the variance of the coefficient in an unrestricted VAR. The pre-selected constants $c_{0}$ and $c_{1}$ must be related as follows: $c_{0}<<c_{1}$. For $\gamma=\left(\gamma_{1}, \ldots, \gamma_{K n}\right)$, the SSVS prior assumes that each element has a Bernoulli form and, hence, for $j=1, \ldots, K n$, we have: $\operatorname{Pr}\left(\gamma_{j}=1\right)=\underline{q}_{j}$ and $\operatorname{Pr}\left(\gamma_{j}=0\right)=1-\underline{q}_{j}$, with $\underline{q}_{j}=0.5$ for all $j$. For $\Sigma$, we use the Wishart prior for $\Sigma^{-1}$, i.e., $\Sigma^{-1} \sim W\left(\underline{S}^{-1}, \underline{v}\right)$. 


\subsection{Stochastic Search Variable Selection (SSVS) Prior for both VAR Coefficient and Error Covariance}

Instead of using $\Sigma^{-1} \sim W\left(\underline{S}^{-1}, \underline{v}\right)$, following George et al. (2008), one can use a SSVS prior for $\Sigma$. Let:

$$
\Sigma^{-1}=\Psi \Psi^{\prime}
$$

where $\Psi$ is upper-triangular. The SSVS prior imposes a standard Gamma prior for square of each of the diagonal elements of $\Psi$ and the SSVS mixture of normal priors for each element above the diagonal. Thus, the diagonal elements of $\Psi$ are always included in the model and ensures a positive definite error covariance matrix.

Let the non-zero elements of $\Psi$ be $\psi_{i j}$ with $\psi=\left(\psi_{11}, \ldots, \psi_{n n}\right)^{\prime}, \eta_{j}=\left(\psi_{1 j}, \ldots, \psi_{j-1, j}\right)^{\prime}$, and $\eta=\left(\eta_{2}^{\prime}, \ldots, \eta_{n}^{\prime}\right)^{\prime}$. For the diagonal elements, prior independence is assumed with:

$$
\psi_{j j}^{2} \sim G\left(\underline{a}_{j}, \underline{b}_{j}\right)
$$

where $G\left(\underline{a}_{j}, \underline{b}_{j}\right)$ denotes the Gamma distribution with mean $\frac{\underline{a}_{j}}{\underline{b}_{j}}$ and variance $\frac{\underline{a}_{j}}{\underline{b}_{j}^{2}}$. We fix $\underline{a}_{j}=\underline{b}_{j}=0.01$ (Koop and Korobilis, 2010). The hierarchical prior for $\eta$ takes the same mixture forms of Normal as discussed above for $\alpha$. For further details, interested readers are referred to George et al. (2008) and Jochmann et al. (2010).

Note, we work with an unrestricted VAR with an intercept and four lags of the eight variables included in every equation. ${ }^{23}$ At this stage, it is important to point out that, ideally, the four US variables should be treated as exogenous, given that South Africa is a small open economy, and hence, the four South African variables should play no part in explaining the behaviour of the US variables. However, we consider all the eight variables as endogenous in the VAR, to be consistent with the DSGE-VAR model, which is estimated using all the eight variables. We do not see this as a problem though, because we are only concerned with forecasting the domestic growth rate, inflation rate and the interest rate, based on their respective equations in the eight variable VAR. Given that each equation has 33 parameters to be estimated and a total of 264 parameters in the system, we consider the following parameterisation of the six priors to provide shrinkage:

${ }^{23}$ The choice of 4 lags is based on the unanimity of the sequential modified LR test statistic, the AIC and the FPE criterion, applied to a stable VAR estimated with the eight variables. Note, stability as usual, implies that no roots were found to lie outside the unit circle. 
- Non-informative Natural Conjugate Prior

We choose: $\underline{\alpha}=0_{K n \times 1}, \underline{V}=100 I_{K \times K}, \underline{v}=0$ and $\underline{S}=0_{n \times n}$.

- Minnesota Prior

Recalling that in our case, all variables have been detrended, we set: $\underline{\alpha}_{M i n}$ to be zero for the lags of all variables. $\Sigma$ is diagonal with elements $s_{i}^{2}$ obtained from univariate regressions of each dependent variable on an intercept and three lags of the eight variables.

- Informative Natural Conjugate Prior

The subjectively chosen hyperparameters of the prior are: $\underline{\alpha}=0_{K n \times 1}, \underline{V}=10 I_{K}$, $\underline{v}=n+1$ and $\underline{S}^{-1}=I_{n}$.

- Independent Normal-Wishart Prior

The subjectively chosen prior hyperparameters are: $\underline{\beta}=0_{K n \times 1}, \underline{V}_{\beta}=10 I_{K n}, \underline{v}=n+1$ and $\underline{S}^{-1}=I_{n}$.

- $S S V S-V A R$

For the SSVS prior for VAR coefficients only, which essentially involves a semi-automatic approach, we choose: $c_{0}=0.1$ and $c_{1}=10$ and a Wishart prior for $\Sigma$ with $\underline{v}=n+1$ and $\underline{S}^{-1}=I_{n}$.

- $S S V S$

For the SSVS on both VAR coefficients and error covariance, we follow the default semi-automatic approach outlined in George et al. (2008), Koop and Korobilis (2010) and Jochmann et al. (2010).

Note that, analytical posterior and predictive results are available only for the first three priors, while, for the last three, we require posterior and predictive simulation. The forecasting results presented below are based on 50,000 MCMC draws using a burn-in of 20,000 (Koop and Korobilis, 2010).

\section{Evaluation of Forecast Accuracy}

Given the specifications of the models, we estimate nine alternative models, namely, the SOENKDSGE-VAR, the classical VAR, six different BVARs and an independently estimated DSGE model, with the latter obtained by setting $\lambda=100,000$ (Hodge et al., 2008), over the period 1980Q1 to 2003Q2, based on quarterly data. Then we compute the out-of-sample 
one- through eight-quarters-ahead forecasts for the period 2003Q3 to 2010Q4, and compare the forecast accuracy of the SOENKDSGE-VAR model with the eight alternative forecasting models. The different types of the VARs and the SOENKDSGE-VAR are estimated with 4 lags of each variable. Since we use 4 lags, the initial 4 quarters of the sample, 1980Q1 to 1980Q4, are used to feed the lags. We generate dynamic forecasts, as would naturally be achieved in actual forecasting practice. The models are re-estimated each quarter over the out-of-sample forecast horizon in order to update the estimate of the coefficients, before producing the 8-quarters-ahead forecasts. This iterative estimation and 8-steps-ahead forecast procedure was carried out for 30 quarters, with the first forecast beginning in 2003Q3. This experiment produced a total of 30 one-quarter-ahead forecasts, 29 two-quarters-ahead forecasts, and so on, up to 23 8-step-ahead forecasts. The RMSEs ${ }^{24}$ for the forecasts are then calculated for the growth rate, CPIX inflation rate and the Repo rate. Note for the SOENKDSGE-VAR model the estimate of $\lambda$ is recursively updated over the out-of-sample period. As in Del Negro and Schorfheide (2004, 2006), Del Negro et al. (2007) and Lees et al. (2011), the percentage gain or loss in the RMSE statistic for the SOENKDSGE-VAR model relative to the eight other alternative models for one- to eight-quarters-ahead forecasts over the period 2003Q3 to 2010Q4 are then examined.

It is important to indicate, that the main reason that we do not forecast the exchange rate is because of the fact that our model cannot be estimated with the exchange rate as an observable variable. This technical detail arises because of two assumptions, namely, international asset markets are complete and that the risk premium on domestic assets relative to foreign assets depends on the difference between foreign and domestic demand shocks. As shown in Alpanda et al., (2010a), one can reestimate a model like ours with the rate of depreciation as an observed variable, by adding a country risk premium shock that allows deviations in the UIP between the policy rates in the home and foreign economies. However, at the time of writing, there was no evidence that would suggest that the use of this method, for closing the open-economy features of the model, would provide better out-of-sample forecasting results. Furthermore, as consumer price inflation and the output gap are of primary importance in the central bank's interest rule, as suggested by Ortiz and Sturzenegger and Alpanda et al., (2010b), we decided to concentrate on forecasting inflation, output growth and the shortterm interest rate only.

\footnotetext{
${ }^{24}$ Note that if $A_{t+h}$ denotes the actual value of a specific variable in period $t+h$ and $F_{t+h}$ is the forecast made in period $t$ for $t+h$, the RMSE statistic can be defined as: $\sqrt{\frac{1}{h} \Sigma\left(A_{t+h}-F_{t+h}\right)^{2}}$. For $h=1$, the summation runs from 2003Q3 to 2010Q4, and for $h=2$, the same covers the period of 2003Q4 to 2010Q4, and so on.
} 
[ Insert Table 3 here ]

In Table 3, we compare the percentage gain (negative entry) or loss (positive entry) in one- to eight-quarters-ahead out-of-sample-forecasts RMSEs by using the SOENKDSGEVAR model over the classical VAR, BVARs and the independently estimated DSGE model, over the period of 2003Q3 to 2010Q4. As Zellner (1986) points out the "optimal" Bayesian forecasts will differ depending upon the loss function employed and the form of predictive probability density function. In other words, Bayesian forecasts are sensitive to the choice of the measure used to evaluate the out-of-sample forecast errors. However, Zellner (1986) points out that the use of the mean of the predictive probability density function for a series, is optimal relative to a squared error loss function and the Mean Squared Error (MSE), and, hence, the RMSE is an appropriate measure to evaluate performance of forecasts, when the mean of the predictive probability density function is used.

For each of the one- to eight-quarters-ahead out-of-sample forecasts, we test whether the gain (loss) in the RMSE from the SOENKDSGE-VAR model relative to the eight other alternative models is significant. For this purpose, we use the Giacomini and White (2006) statistic. This test of equal forecasting accuracy can handle forecasts based on both nested and non-nested models, regardless of the estimation procedures used for the derivation of the forecasts, including Bayesian methods. Recall that, the DSGE-VAR approach nests the VAR and the independently estimated DSGE models, as well as the VAR models.

The conclusions, regarding the three variables of concern, based on the percentage gain or loss in RMSEs by using the SOENKDSGE-VAR relative to the eight other alternative models for one- to eight-quarters-ahead forecasts, ${ }^{25}$ from these tables can be summarised as follows:

Out-of-Sample (2003Q3-2010Q4) Comparisons:

\section{Inflation Rate}

The SOENKDSGE-VAR model is found to consistently outperform the classical VAR, and the other BVAR models numbered 1 through 5, with the exception of one or two cases as

${ }^{25}$ For the sake of completeness, we also analysed the in-sample one-step-ahead RMSEs over the entire sample period of 1980Q1-2010Q4 for the different models. Overall, with the exception of the inflation rate in some instances, the SOENKDSGE-VAR model provides competitive forecasts in relation to the eight alternative models. These results are available upon request from the authors. 
far as forecasting CPIX inflation rate is concerned. But the SOENKDSGE-VAR model is, in turn, outperformed by the BVAR model based on the SSVS prior on both the VAR coefficients and the error covariance, barring the sixth-quarter-ahead forecast. However, there exists only significant differences at the seventh and eight-quarters-ahead horizons. Finally, the SOENKDSGE-VAR model outperforms the independently estimated SOENKDSGE, except for the first- and second-steps-ahead forecasts, but the Giacomini and White (2006) test statistic is not significant for any of the one- to eight-quarters-ahead forecasts;

\section{Growth Rate}

The SOENKDSGE-VAR model is found to consistently and significantly outperform the classical VAR and the all the BVAR models, barring the BVAR model based on the SSVS prior on both the VAR coefficients and the error covariance. The results are a bit mixed when we compare the SOENKDSGE-VAR model relative to the BVAR with the SSVS prior on both the VAR coefficients and the error covariance. While, the SSVS model ouperforms the SOENKDSGE-VAR insignificantly at the third-quarter-ahead, and significantly at fourth-, fifth- and sixth-quarters-ahead, the former is in turn outperformed significantly at the first- and second-quarters-ahead, and not significantly at the seventh and eighth steps. Finally, the SOENKDSGE-VAR model is also outperformed by the independently estimated SOENKDSGE, but, the Giacomini and White (2006) test statistic is not significant for any of the one- to eight-quarters-ahead forecasts;

\section{Interest Rate}

The SOENKDSGE-VAR model is found to consistently and in majority of the cases significantly outperform the classical VAR and the BVAR models based on the Minnesota prior and the non-informative natural conjugate prior. This result continues to hold as far as the other BVAR models are concerned, barring some of the longer-horizon forecasts from the BVAR models based on the informative natural conjugate prior, the independent normal-

Wishart prior and the SSVS prior on the VAR coefficients, but, in none of these cases in a significant manner. As far as the BVAR based on the SSVS prior on both VAR coefficients and the error covariance is concerned, this model outperforms the SOENKDSGE-VAR at all the steps, and majority of them in a significant fashion, barring the first two horizons. Finally, the SOENKDSGE-VAR model is found to outperform the independently estimated SOENKDSGE model at longer horizons, beyond the fifth-step-ahead forecasts. However, as with the inflation rate and the growth rate, the Giacomini and White (2006) test statistic is not significant for any of the one- to eight-quarters-ahead forecasts. 
Some additional insights into the relative forecasting performances of the alternative models can be obtained by comparing plots of the actual values and the forecasted values from each model as new information becomes available at the beginning of every quarter, over the outof-sample horizon. In a series of figures, we compare the forecasts from the SOENKDSGEVAR with those of the best performing atheoretical model, namely the BVAR model based on the SSVS prior on both the VAR coefficients and the error covariance matrix (BVAR6). Figures 2, 3 and 4 compares the forecasts generated from the DSGE model with the actual values over the period of 2003Q3 till 2010Q4, while, Figures 5, 6 and 7 does the same from the BVAR6 model. Note, we plot the eight-quarters-ahead ex ante forecasts over the period of 2003Q3 till 2009Q1 and seven, six, five, four, three, two and one-steps ahead forecasts over 2009Q2 till 2010Q4. When we compare, the forecasts across the two models for the three variables, it is evident as to why the BVAR6 model is the relatively better model. The BVAR6 model tracks the data in general much more closely than the SOENKDSGE-VAR model, and, hence, produces lower RMSEs over the one- to eight-quarters-ahead forecasts. ${ }^{26}$

\section{[ Insert Figures 2 to 7 here ]}

So overall, even though the SOENKDSGE-VAR and SOENKDSGE cannot be separated, more importantly, the SOENKDSGE model performs competitively, if not better than all other VAR models, with the exception of the BVAR model based on the SSVS prior on both VAR coefficients and the error covariance. Given this, it is important to analyze the specific features, especially the role played by the seven different nominal and real rigidities in the forecasting performance of the SOENKDSGE-VAR model. Recall the seven rigidities considered in our model are: wage indexation to past consumer inflation, domestic price inflation indexation to its past values, imperfect exchange rate pass-through, the degree of stickiness in domestic prices, wages and imported prices and the degree of habit persistence. We consider the full-sample one-step-ahead RMSEs of the SOENKDSGE-VAR model without a specific rigidity relative to the RMSE of the SOENKDSGE-VAR model inclusive of

\footnotetext{
${ }^{26}$ Note that, barring few exceptions, the DSGE-VAR model does quite well at providing low forecast errors for inflation when the rate of inflation is both low and high over various horizons. In light of this, we compared the DSGE-VAR and the SSVS prior on both the VAR coefficients and the error covariance over one- to eight-quarters ahead for the period 2004Q1-2007Q1 and 2008Q1-2009Q1. For the first sub-out-ofsample period, the DSGE-VAR outperformed the SSVS prior on both the VAR coefficients and the error covariance in terms of average RMSEs for the inflation rate and the interest rate, but not the growth rate. For the latter smaller-sub-sample, the SSVS prior on both the VAR coefficients and the error covariance outperformed all the three variables based on average RMSEs for one- to five-quarters-ahead forecasts. These results are available upon request from the authors.
} 
all rigidities. As can be seen from Table 4, for the inflation rate, wage indexation, imperfect exchange rate pass-through, the degree of stickiness in domestic price, imported price and wage improves the forecasting power of the model. For output, all the seven rigidities play a role, while for the interest rate, the wage inflation indexation, imperfect exchange rate pass-through, domestic price and wage stickiness adds to the forecasting power. However, for all the three variables, the most important form of rigidity is the Calvo (1983)-type domestic price stickiness. Imposing this rigidity would tend to improve the forecasting power of the SOENKDSGE-VAR model by a substantial degree. Note that, the importance of the domestic price stickiness in improving the forecasting ability of the model is not surprising, in light of the sizeable literature on the issue of the importance of constant mark-ups and price-rigidities in South Africa (see for example Feddreke and Hill, 2011, and references cited therein.)

\section{[ Insert Table 4 here ]}

At, the same time, it is also important to understand why the BVAR model based on the SSVS prior on both VAR coefficients and the error covariance performs so well amongst all the atheoretical models. Recall that, the SSVS prior, is like automatically selecting a restricted VAR, based on data, since depending on whether the posterior inclusion probability of a specific coefficient exceeds 0.5 or not, a particular lagged dependent variable can be included or deleted from the model. Note, since this is done at each recursion, the posterior inclusion probabilities, and, hence the model can be different at different points in time. As the results indicate, the forecasting performance of a BVAR model cannot only be improved by imposing the SSVS prior on the VAR coefficients, the same needs to be done also for the error covariance, $\Sigma$ with $\Sigma^{-1}=\Psi \Psi^{\prime}$ where $\Psi$ is upper-triangular. The SSVS prior imposes a standard Gamma prior for square of each of the diagonal elements of $\Psi$ and the SSVS mixture of normal priors for each element above the diagonal, rather than a Wishart prior. We generally observe that for each recursion over the out-of-sample horizon only 25 to 35 coefficients amongst the possible 264 VAR coefficients are included, while at the most 2 to 3 elements are chosen for the error covariance, besides all the eight diagonal entries. ${ }^{27}$ Clearly, the economization of the parameter space improves the out-of-sample forecasting performance of the BVAR model with SSVS prior on both VAR coefficients and the error covariance. $^{28}$

${ }^{27}$ Details of these results have not been presented here to save space. They are, however, available upon request from the authors.

${ }^{28}$ These results could also suggest that the use of time-varying parameter models may provide improved 
As a final observation: Our paper follows in a long tradition of forecasting horseraces between structural and time-series models. In other words, the issue involves the tradeoff between designing a model that fits the data generated by the true data generating process. Structural economic modeling employs economic theory to describe how the variables in a system relate to each other. Such models by their nature must be simplifications from the actual structural model generating the data series. Atheoretical time-series models come with the advantage of flexibility in fitting the observed data without imposing any economic structure. An interesting observation is that if we had limited our analysis of the BVAR models to the Minnesota prior, as done in the literature, then the DSGE-VAR model would win the horserace. But allowing for more sophisticated versions of BVAR models; especially the SSVS prior, we find that the BVAR model with a SSVS prior on both VAR coefficients and the error covariance tends to perform better than the DSGE-VAR model. This may imply, at least based on our application, that as long as the structural model is a significant simplification of the actual structural model of the economy, then a time-series model may always outperform the structural model. This line of thinking possibly explains why time series models have tended to outperform simplistic DSGE models in the context of South Africa, as discussed in the introduction. To put it differently, we highlight the need to develop elaborate structures for the DSGE model to capture the true dynamics of the data, which, in turn would allow us to win the race against the VAR-type models. In our case, the wide variety of rigidities helps in creating this more sophisticated framework, and as shown above, it is the imposition of these rigidities that help in outperforming the basic (B)VAR models. Further, recall that the DSGE-VAR model can be interpreted as imposing Bayesian priors on the VAR model from the structural DSGE model. Our results indicate that the DSGE framework developed in this paper is in itself quite competent, and does not necessarily require a combined approach involving the DSGE and VAR models to outperform the type of (B)VAR models traditionally used in the literature.

\section{Conclusion}

In many instances, the forecasting performance of theoretical DSGE models are unable to consistently outperform certain VAR or BVAR models, when applied to South African macroeconomic data. Against this backdrop, we develop a SOENKDSGE-VAR model of the South African economy, characterised by incomplete pass-through of exchange rate changes,

forecasting performance, particular when seeking to model a small-open emerging economy that is subject to a greater degree of economic variability. 
external habit formation, partial indexation of domestic prices and wages to past inflation, and staggered price and wage setting. The model is estimated using Bayesian techniques on data for South Africa and the US from the period 1980Q1 to 2003Q2, and then used to forecast output growth, inflation and a measure of nominal short-term interest rate for oneto eight-quarters-ahead over an out-of-sample horizon of 2003Q3 to 2010Q4. The forecast performance of the SOENKDSGE-VAR model is then compared with an independently estimated DSGE model, the classical VAR and BVAR models, with the latter being estimated based on six alternative priors, namely, Non-Informative and Informative Natural Conjugate priors, the Minnesota prior, Independent Normal-Wishart Prior, SSVS prior on VAR coefficients and SSVS prior on both VAR coefficients and error covariance.

Overall, for the three variables, we can make following important observations: First, as far as out-of-sample is concerned, barring the BVAR model based on the SSVS prior on both VAR coefficients and the error covariance, the SOENKDSGE-VAR model is found to perform competitively, if not better than all the other VAR models for most of the oneto eight-quarters-ahead forecasts. Second, there is no significant gain in forecasting performance by moving to a DSGE-VAR framework when compared to an independently estimated SOENKDSGE model, both within and out-of-sample. Combining the two observations made above, we can conclude that the DSGE framework, developed in this paper, is in itself quite competent, and, does not require a combined approach involving the DSGE and VAR models, whereby macroeconomic theory of the DSGE model is utilised to provide priors to an otherwise completely atheoretical VAR model. Third, when we analyze the role played by the seven different rigidities in the forecasting power of the SOENKDSGE-VAR model, we find that though all the rigidities seem to matter for the three variables, but the Calvo (1983)type staggered domestic price setting behavior adds the most to the forecasting power of the SOENKDSGE-VAR model. Finally, based on the out-of-sample forecasting exercise, there is quite strong evidence that the BVAR model based on the SSVS prior on both VAR coefficients and the error covariance, is the best-suited model in forecasting the three variables of interest. 


\section{References}

Adjemian, S., Pariès, M.D. and Moyen, S. (2008). Towards a monetary policy evaluation framework. Working Paper Series 942, European Central Bank.

Alpanda, S., Kotzé, K. and Woglom, G. (2010a). The role of the exchange rate in a South African New Keynesian DSGE model. South African Journal of Economics, 78, 170-191.

Alpanda, S., Kotzé, K. and Woglom, G. (2010b). Should Central Banks of Small Open Economies Respond to Exchange Rate Fluctuations? The Case of South Africa. Economic Research Southern Africa, Working Paper No. 174.

Alpanda, S., Kotzé, K. and Woglom, G. (2011). Forecasting performance of an estimated DSGE model for the South African economy. South African Journal of Economics, 79, 50-67.

An, S. and Schorfheide, F. (2007). Bayesian Analysis of DSGE Models. Econometric Reviews, 26, 113-172.

Bhardwaj, G. and Swanson, N.R. (2006). An empirical investigation of the usefulness of ARFIMA models for predicting macroeconomic and financial time series. Journal of Econometrics, 131, 539-578.

Calvo, G. (1983). Staggered prices in a utility-maximising framework, Journal of Monetary Economics, Vol. 12, pp. 983-998.

Chari, V.V., Kehoe, P. and McGratten, E. (2002). Can Sticky Price Models Generate Volatile and Persistent Real Exchange Rates? Review of Economic Studies, Vol. 69, pp. 533-563.

Clark, T.E. and McCracken, M.W. (2001). Tests of equal forecast accuracy and encompassing for nested models. Journal of Econometrics, 105, 85-110.

Del Negro, M., Schorheide, F., Smets, F. and Wouters, R. (2007). On the Fit of New Keynesian Models. Journal of Business and Economic Statistics, 25, 123-143.

Del Negro, M. and Schorfheide, F. (2003). Take your model bowling: Forecasting with general equilibrium models. Federal Reserve Bank of Atlanta Economic Review, Fourth Quarter, 35-49.

Del Negro, M. and Schorfheide, F. (2004). Priors from General Equilibrium Models for VARs. International Economic Review, 45, 643-673.

Doan, T., Litterman, R. and Sims, C. (1984). Forecasting and conditional projection using realistic prior distributions. Econometric Reviews, 3, 1-144. 
Fedderke, J.W. and Hill, A.J. (2011). Industry structure and labor market flexibility in the South African manufacturing sector: A time series and panel data approach. Economic Modelling, 28, 1291-1302.

George, E., Sun, D. and Ni, S. (2008). Bayesian stochastic search for VAR model restrictions. Journal of Econometrics, 142, 553-580.

Geweke, J. (1999). Using Simulation Methods for Bayesian Econometric Models: Inference, Development, and Communication. Econometric Review, 18, 1-73.

Giacomini, R., and White, H. (2006). Tests of conditional predictive ability. Econometrica, $74,1545-1578$.

Gupta, R. and Kabundi, A. (Forthcoming). A Dynamic Factor Model for Forecasting Macroeconomic Variables in South Africa. International Journal of Forecasting.

Gupta, R. and Kabundi, A. (2010). Forecasting Macroeconomic Variables in a Small Open Economy: A Comparison between Small- and Large-Scale Models. Journal of Forecasting, 29, 168-185.

Hodge, A. Robinson, T., and Stuart, R. (2008). A Small BVAR-DSGE Model for Forecasting the Australian Economy. Reserve Bank of Australia Discussion Paper, RDP 2008-04.

Jochmann, M., Koop, G. and Strachan, R. (2010). Bayesian Forecasting using Stochastic Search Variable Selection in a VAR Subject to Breaks. International Journal of Forecasting, 26, 326-347.

Justiniano, A and Preston, B. 2004. Small Open Economy DSGE models: Specification, Estimation and Model Fit. Unpublished manuscript.

Justiniano, A and Preston, B. 2010. Monetary Policy and Uncertainty in an Emprical Small Open Economy Models. Journal of Applied Econometrics, 25, 93-128.

Koop, G. and Korobilis, D. (2010). Bayesian Multivariate Time Series Methods for Empirical Macroeconomics. Foundations and Trends in Econometrics, 3, 267-358.

Lees, K. Matheson, T., and Smith, C. (2011). Open Economy DSGE-VAR Forecasting and Policy Analysis: Head to Head with the RBNZ, International Journal of Forecasting, 27, 512-528.

Litterman, R. (1986). Forecasting with Bayesian vector autoregressions Five years of experience. Journal of Business and Economic Statistics, 4, 25-38.

Liu, G.D., Gupta, R. and Schaling, E. (2010). Forecasting the South African Economy: A 
Hybrid-DSGE Approach. Journal of Economic Studies, 37, 181-195.

Liu, G.D., Gupta, R. and Schaling, E. (2009). A New-Keynesian DSGE Model for Forecasting the South African Economy. Journal of Forecasting, 28, 387-404.

Liu, G.D. and Gupta, R. (2007). A Small-Scale DSGE Model for Forecasting the South African Economy. South African Journal of Economics, 75,179-193.

Lubik, T. and Schorfheide, F. (2005). A Bayesian look at new open economy macroeconomics. NBER Macroeconomics Annual, pp. 313-366.

Lucas, R. (1976). Econometric Policy Evaluation: A Critique, in Brunner, K. Meltzer, A. The Phillips Curve and Labor Markets, Carnegie-Rochester Conference Series on Public Policy, 1, pp. 19-46.

Monacelli, T. 2005. Monetary Policy in a Low Pass-Through Environment. Journal of Money Credit and Banking, 37, pp. 1047-1066.

McCracken, M.W. (1999). Asymptotics for Out of Sample Tests of Causality, Working Paper, Louisiana State University.

Newey, W.K. and West, K.D. (1987). A Simple, Positive Semi-definite, Heteroskedasticity and Autocorrelation Consistent Covariance Matrix. Econometrica, 55, 703-808.

Ortiz, A. and Sturzenegger, F. (2007). Estimating SARB'S Policy Reaction Rule. South African Journal of Economics, Economic Society of South Africa, 75, 659-680.

Schorfheide, F. and Del Negro, M. (2003). Take Your Model Bowling: Forecasting with General Equilibrium Models. Federal Reserve Bank of Atlanta, Economic Review, 88, Number 4.

Smets, F. and Wouters, R. (2007). Shocks and frictions in US business cycles: A Bayesian DSGE approach. American Economic Review, 97, 586-606.

Steinbach, M.R., Mathuloe, P.T. and Smit, B.W. (2009). An open economy New Keynesian DSGE model of the South African economy. South African Journal of Economics, 77, 207227.

Theil, H. and Goldberger, A.S. (1961). On pure and mixed estimation in economics. International Economic Review, 2, 6578.

West, K.D. (2006). Forecast Evaluation. In Handbook of Economic Forecasting, eds. Elliot, G. and Granger, C.W.J; Timmerman, A. London: North Holland, Vol. 1.

West, K.D. (1996). Asymptotic Inference about Predictive Ability. Econometrica, 64, 10671084 . 
Zellner, A. (1986). A Tale of Forecasting 1001 Series: The Bayesian Knight Strikes Again. International Journal of Forecasting, 92, 491-494. 


\section{Appendix}

\section{The full-log-linearised model}

CPI inflation, quarter-on-quarter

$$
\pi_{t}=(1-\gamma) \pi_{t}^{h}+\gamma \pi_{t}^{f}
$$

CPI inflation, year-on-year

$$
\pi_{4, t}=\left(\pi_{t}+\pi_{t-1}+\pi_{t-2}+\pi_{t-3}\right) / 4
$$

Domestic inflation

$$
\pi_{t}^{h}=\frac{\omega}{1+\omega \beta} \pi_{t-1}^{h}+\frac{\beta}{1+\omega \beta} E_{t} \pi_{t+1}^{h}+\frac{\left(1-\theta_{h}\right)\left(1-\theta_{h} \beta\right)}{\theta_{h}(1+\omega \beta)} m c_{t}
$$

Marginal costs

$$
m c_{t}=r w_{t}-a_{t}+\gamma s_{t}+\varepsilon_{t}^{p},
$$

Real wages

$$
r w_{t}=r w_{t-1}+\pi_{t}^{w}-\pi_{t}
$$

Nominal wage inflation

$$
\pi_{t}^{w}=\alpha \pi_{t-1}+\beta E_{t} \pi_{t+1}^{w}-\alpha \beta \pi_{t}+\frac{\left(1-\theta_{w}\right)\left(1-\theta_{w} \beta\right)}{\theta_{w}\left(1+\varphi \xi_{w}\right)} \mu_{t}^{w}
$$

Wage markup

$$
\mu_{t}^{w}=\frac{\sigma}{1-h}\left(c_{t}-h c_{t-1}\right)+\varphi\left(y_{t}-a_{t}\right)-r w_{t}
$$

Imported inflation

$$
\pi_{t}^{f}=\beta E_{t} \pi_{t+1}^{f}+\frac{\left(1-\theta_{f}\right)\left(1-\theta_{f} \beta\right)}{\theta_{f}} \psi_{t}
$$

Law of one price gap

$$
\psi_{t}=q_{t}-(1-\gamma) s_{t}
$$

Terms of trade

$$
s_{t}=s_{t-1}+\pi_{t}^{f}-\pi_{t}^{h}
$$

UIP condition

$$
E_{t} q_{t+1}=q_{t}+\left(r_{t}-E_{t} \pi_{t+1}\right)-\left(r_{t}^{*}-E_{t} \pi_{t+1}^{*}\right)+\phi_{t},
$$


Taylor rule

$$
r_{t}=\rho_{r} r_{t-1}+\left(1-\rho_{r}\right)\left[\phi_{\pi} \pi_{4, t+1}+\phi_{y} y_{t}\right]+\varepsilon_{t}^{r}
$$

Aggregate supply

$$
y_{t}=a_{t}+l_{t}
$$

Aggregate demand

$$
y_{t}=(1-\gamma) c_{t}+\eta \gamma(2-\gamma) s_{t}+\gamma y_{t}^{*}+\eta \gamma \psi_{t}
$$

Risk sharing condition

$$
y_{t}^{*}=h y_{t-1}^{*}+\frac{\sigma}{\sigma^{*}}\left(c_{t}-h c_{t-1}\right)-\frac{1-h}{\sigma^{*}} q_{t}
$$

Price markup shock, $\operatorname{ARMA}(1,1)$

$$
\varepsilon_{t}^{p}=\rho_{p} \varepsilon_{t-1}^{p}+\nu_{t}^{p}+\mu_{p} \nu_{t-1}^{p}
$$

Demand shock, AR(1)

$$
\varepsilon_{t}^{d}=\rho_{d} \varepsilon_{t-1}^{d}+\nu_{t}^{d}
$$

Productivity shock, AR(1)

$$
a_{t}=\rho_{a} a_{t-1}+\nu_{t}^{a}
$$

Foreign inflation, quarter-on-quarter

$$
\pi_{t}^{*}=\frac{\omega^{*}}{1+\omega^{*} \beta} \pi_{t-1}^{*}+\frac{\beta}{1+\omega^{*} \beta} E_{t} \pi_{t+1}^{*}+\frac{\left(1-\theta^{*}\right)\left(1-\theta^{*} \beta\right)}{\theta^{*}\left(1+\omega^{*} \beta\right)} m c_{t}^{*}
$$

Foreign inflation, year-on-year

$$
\pi_{4, t}^{*}=\left(\pi_{t}^{*}+\pi_{t-1}^{*}+\pi_{t-2}^{*}+\pi_{t-3}^{*}\right) / 4
$$

Foreign marginal costs

$$
m c_{t}^{*}=r w_{t}^{*}-a_{t}^{*}+\varepsilon_{t}^{p *},
$$

Foreign real wages

$$
r w_{t}^{*}=r w_{t-1}^{*}+\pi_{t}^{w *}-\pi_{t}^{*}
$$

Foreign nominal wage inflation

$$
\pi_{t}^{w *}=\alpha \pi_{t-1}^{*}+\beta E_{t} \pi_{t+1}^{w *}-\alpha \beta \pi_{t}^{*}+\frac{\left(1-\theta_{w}^{*}\right)\left(1-\theta_{w}^{*} \beta\right)}{\theta_{w}^{*}\left(1+\varphi^{*} \xi_{w}\right)} \mu_{t}^{w *}
$$


Foreign wage markup

$$
\mu_{t}^{w *}=\frac{\sigma}{1-h}\left(y_{t}^{*}-h y_{t-1}^{*}\right)+\varphi l^{*}-r w_{t}^{*}
$$

Foreign Taylor rule

$$
r_{t}^{*}=\rho_{r}^{*} r_{t-1}^{*}+\left(1-\rho_{r}^{*}\right)\left[\phi_{\pi}^{*} \pi_{4, t+1}^{*}+\phi_{y}^{*} y_{t}^{*}\right]+\varepsilon_{t}^{r *}
$$

Foreign Euler equation

$$
y_{t}^{*}=\frac{1}{1+h} E_{t} y_{t+1}^{*}+\frac{h}{1+h} y_{t-1}^{*}-\frac{1-h}{\sigma^{*}(1+h)}\left[r_{t}^{*}-E_{t} \pi_{t+1}^{*}+\varepsilon_{t}^{d *}\right]
$$

Foreign aggregate supply

$$
y_{t}^{*}=a_{t}^{*}+l_{t}^{*}
$$

Foreign price shock, $\operatorname{ARMA}(1,1)$

$$
\varepsilon_{t}^{p *}=\rho_{p}^{*} \varepsilon_{t-1}^{p *}+\nu_{t}^{p *}+\mu_{p}^{*} \nu_{t-1}^{p *}
$$

Foreign demand shock, AR(1)

$$
\varepsilon_{t}^{d *}=\rho_{d}^{*} \varepsilon_{t-1}^{d *}+\nu_{t}^{d *}
$$

Foreign productivity shock, AR(1)

$$
a_{t}^{*}=\rho_{a}^{*} a_{t-1}^{*}+\nu_{t}^{a *}
$$

\begin{tabular}{|c|c|}
\hline Observed series & Source \\
\hline \multicolumn{2}{|l|}{ South Africa } \\
\hline Real Gross Domestic Product & South African Reserve Bank (SARB) \\
\hline Headline CPI inflation & StatsSA, SARB, Authors' own calculations \\
\hline Repurchase rate & South African Reserve Bank \\
\hline Real unit labour costs & Authors' own calculations, SARB \\
\hline \multicolumn{2}{|l|}{ United States } \\
\hline Real GDP & Federal Reserve Bank of St. Louis \\
\hline GDP deflator & Federal Reserve Bank of St. Louis \\
\hline Federal Funds rate & Federal Reserve Bank of St. Louis \\
\hline Average Weekly Hours worked (Total Private Industries) & Federal Reserve Bank of St. Louis \\
\hline
\end{tabular}

Risk premium

$$
\phi_{t}=\varepsilon_{t}^{d}-\varepsilon_{t}^{d *}
$$

Table A.1: Data sources 
Table 1: Key Calibrated Parameters

\begin{tabular}{llllllll}
\hline$\beta$ & $\varphi$ & $\xi_{w}$ & $h$ & $\gamma$ & $\rho_{r}$ & $\rho_{r}^{*}$ & $\alpha^{*}$ \\
\hline 0.99 & 3 & 1 & 0.7 & 0.2 & 0.73 & 0.75 & 0.5 \\
\hline
\end{tabular}


Table 2: Prior Distributions and Posterior Estimates

\begin{tabular}{|c|c|c|c|c|c|c|}
\hline Parameter description & & $\begin{array}{l}\text { Prior } \\
\text { density }\end{array}$ & $\begin{array}{l}\text { Prior } \\
\text { mean }\end{array}$ & $\begin{array}{l}\text { Prior } \\
\text { std dev }\end{array}$ & $\begin{array}{l}\text { Posterior } \\
\text { mean }\end{array}$ & $\begin{array}{l}\text { Posterior } \\
\mathbf{9 0 \%} \text { interval }\end{array}$ \\
\hline \multicolumn{7}{|c|}{ Domestic economy } \\
\hline \multicolumn{7}{|l|}{ Structural parameters } \\
\hline Consumption substitution elasticity & $\sigma$ & $N$ & 1 & 0.2 & 1.107 & $0.804 ; 1.360$ \\
\hline Home/foreign substitution & $\eta$ & $G$ & 1 & 0.2 & 0.689 & $0.490 ; 0.887$ \\
\hline Calvo: domestic prices & $\theta_{h}$ & $B$ & 0.75 & 0.1 & 0.632 & $0.571 ; 0.689$ \\
\hline Calvo: imported prices & $\theta_{f}$ & $B$ & 0.75 & 0.1 & 0.794 & $0.670 ; 0.914$ \\
\hline Calvo: wages & $\theta_{w}$ & $B$ & 0.75 & 0.1 & 0.754 & $0.661 ; 0.853$ \\
\hline Indexation: home prices & $\omega$ & $B$ & 0.5 & 0.1 & 0.165 & $0.090 ; 0.240$ \\
\hline Indexation: wages & $\alpha$ & $B$ & 0.5 & 0.1 & 0.634 & $0.493 ; 0.775$ \\
\hline \multicolumn{7}{|l|}{ Taylor rule weights } \\
\hline Inflation & $\phi_{\pi}$ & $G$ & 1.5 & 0.125 & 1.336 & {$[1.202 ; 1.462$} \\
\hline Output gap & $\phi_{y}$ & $G$ & 0.125 & 0.031 & 0.202 & $0.130 ; 0.271$ \\
\hline \multicolumn{7}{|l|}{ Persistence parameters } \\
\hline $\operatorname{AR}(1):$ demand & $\rho_{d}$ & $B$ & 0.8 & 0.1 & 0.72 & $0.617 ; 0.824$ \\
\hline $\mathrm{AR}(1)$ : productivity & $\rho_{a}$ & $B$ & 0.8 & 0.1 & 0.934 & $0.924 ; 0.950$ \\
\hline $\mathrm{AR}(1)$ : price markups & $\rho_{p}$ & $B$ & 0.8 & 0.1 & 0.662 & $0.537 ; 0.795$ \\
\hline MA(1): price markups & $\mu_{p}$ & $B$ & 0.8 & 0.1 & 0.89 & $0.832 ; 0.948$ \\
\hline \multicolumn{7}{|c|}{ Standard deviations of domestic shocks } \\
\hline iid shock: productivity & $\sigma_{a}$ & $I G$ & 1 & $\infty$ & 0.574 & $0.430 ; 0.716$ \\
\hline iid shock: demand & $\sigma_{d}$ & $I G$ & 1 & $\infty$ & 0.469 & $0.313 ; 0.629$ \\
\hline iid shock: price markups & $\sigma_{p}$ & $I G$ & 1 & $\infty$ & 0.755 & $0.585 ; 0.917$ \\
\hline iid shock: monetary policy & $\sigma_{r}$ & $I G$ & 1 & $\infty$ & 0.208 & $0.174 ; 0.243$ \\
\hline \multicolumn{7}{|c|}{ Foreign economy } \\
\hline \multicolumn{7}{|l|}{ Structural parameters } \\
\hline Consumption substitution elasticity & $\sigma$ & $N$ & 1 & 0.2 & 1.145 & $0.962 ; 1.360$ \\
\hline Calvo: prices & $\theta^{*}$ & $B$ & 0.75 & 0.1 & 0.595 & $0.470 ; 0.729$ \\
\hline Calvo: wages & $\theta_{w}^{*}$ & $B$ & 0.75 & 0.1 & 0.585 & $0.445 ; 0.710$ \\
\hline Indexation: prices & $\omega^{*}$ & $B$ & 0.5 & 0.1 & 0.377 & $0.216 ; 0.529$ \\
\hline \multicolumn{7}{|l|}{ Taylor rule weights } \\
\hline Inflation & $\phi_{\pi}$ & $G$ & 1.5 & 0.125 & 2.176 & $1.763 ; 2.577$ \\
\hline Output gap & $\phi_{y}$ & $G$ & 0.125 & 0.031 & 0.117 & $0.078 ; 0.151$ \\
\hline \multicolumn{7}{|l|}{ Persistence parameters } \\
\hline $\operatorname{AR}(1):$ productivity & $\rho_{a}^{*}$ & $B$ & 0.8 & 0.1 & 0.918 & $0.889 ; 0.949$ \\
\hline $\operatorname{AR}(1):$ demand & $\rho_{d}^{*}$ & $B$ & 0.8 & 0.1 & 0.706 & $0.589 ; 0.819$ \\
\hline $\operatorname{AR}(1)$ : price markups & $\rho_{p}^{*}$ & $B$ & 0.8 & 0.1 & 0.641 & $0.436 ; 0.859$ \\
\hline MA(1): price markups & $\mu_{w}^{*}$ & $B$ & 0.5 & 0.1 & 0.428 & $0.262 ; 0.584$ \\
\hline \multicolumn{7}{|c|}{ Standard deviations of foreign shocks } \\
\hline iid shock: productivity & $\sigma_{a}^{*}$ & $I G$ & 1 & $\infty$ & 0.218 & $0.178 ; 0.256$ \\
\hline iid shock: demand & $\sigma_{d}^{*}$ & $I G$ & 1 & $\infty$ & 0.342 & $0.229 ; 0.442$ \\
\hline iid shock: price markups & $\sigma_{p}^{*}$ & $I G$ & 1 & $\infty$ & 0.482 & $0.275 ; 0.694$ \\
\hline iid shock: monetary policy & $\sigma_{r}^{*}$ & $I G$ & 1 & $\infty$ & 0.146 & $0.127 ; 0.166$ \\
\hline \multicolumn{7}{|c|}{ DSGE-VAR } \\
\hline Relative weight of DSGE model & $\hat{\lambda}$ & $U_{(0,10)}$ & - & - & 0.726 & {$[0.625 ; 0.812$} \\
\hline
\end{tabular}




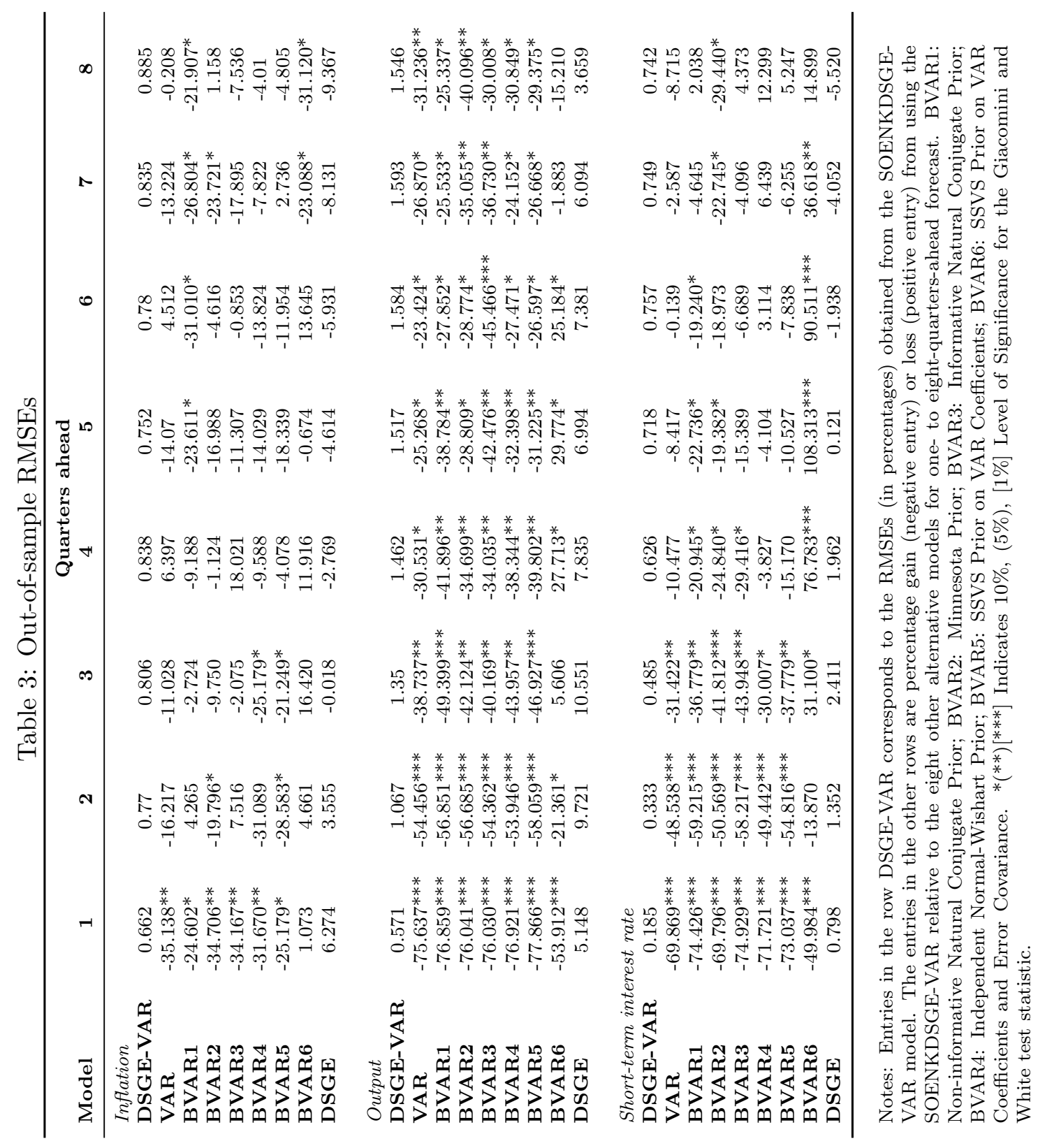


Table 4: Individual rigidities' contributions to forecasting performance

\begin{tabular}{lrrrrrrr}
\hline & \multicolumn{7}{c}{ Excluded rigidity } \\
Variable & $\alpha$ & $\omega$ & $\varphi$ & $\theta_{h}$ & $\theta_{f}$ & $\theta_{w}$ & $h$ \\
\hline Inflation & 1.017 & 0.928 & 1.032 & 124.114 & 1.041 & 1.272 & 0.994 \\
Output Growth & 1.063 & 1.007 & 1.139 & 66.763 & 1.070 & 1.504 & 1.392 \\
Short-Term Interest Rate & 1.022 & 0.972 & 1.010 & 51.803 & 0.998 & 1.175 & 0.993 \\
\hline
\end{tabular}

Notes: $\alpha$ : Wage Inflation Indexation to Past Consumer Inflation; $\omega$ : Home Price Inflation Indexation to its Past Values; $\varphi$ : Imperfect Exchange Rate Pass-Through; thet $a_{h}$ : Degree of Domestic Price Stickiness; $\theta_{f}$ : Degree of Imported Price Stickiness; $\theta_{w}$ : Degree of Wage Stickiness; $h$ : Degree of Habit Persistence. 
Figure 1: Data plots

South Africa: Output

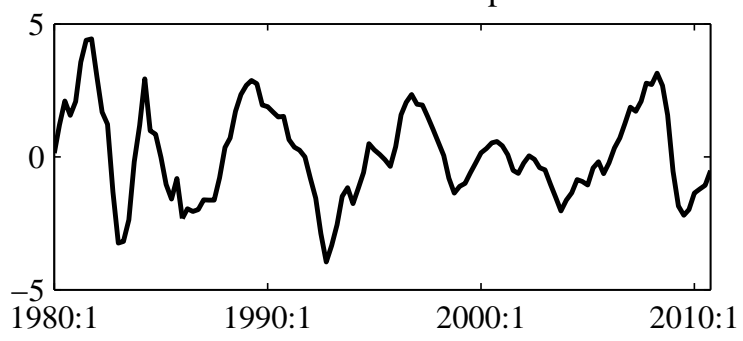

South Africa: CPI inflation, y/y

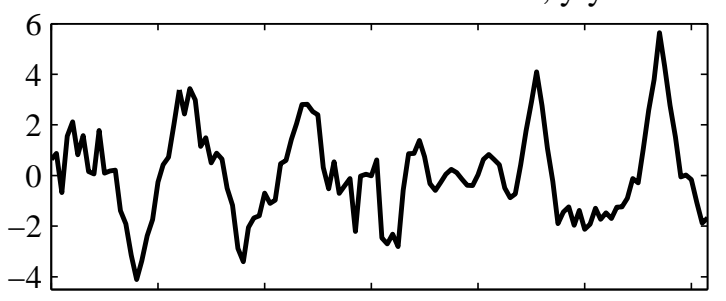

1980:1 1985:1 1990:1 1995:1 2000:1 2005:1 2010:1

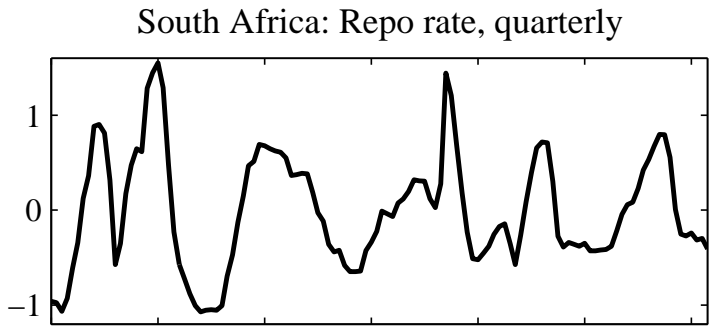

1980:1 1985:1 1990:1 1995:1 2000:1 2005:1 2010:1

South Africa: Marginal cost

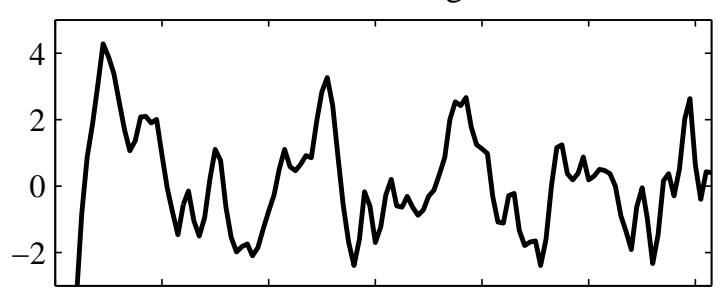

1980:1 1985:1 1990:1 1995:1 2000:1 2005:1 2010:1
US: Output

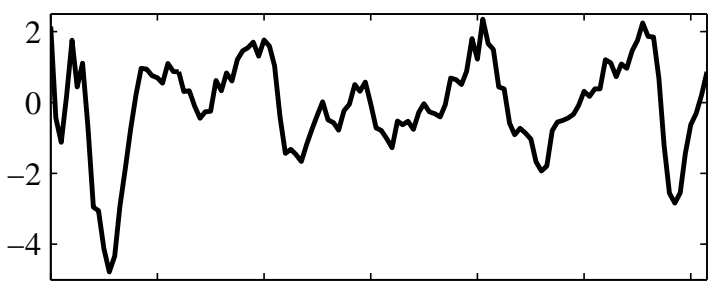

1980:1 1985:1 1990:1 1995:1 2000:1 2005:1 2010:1

US: GDP deflator, y/y

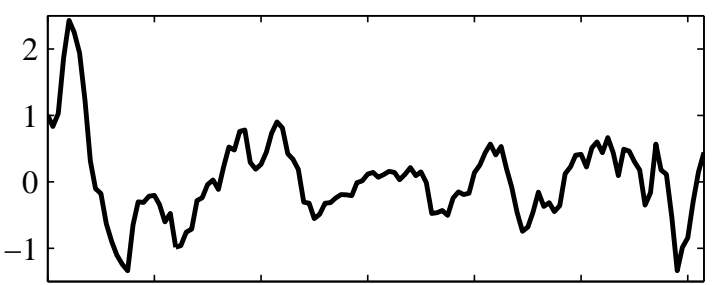

1980:1 1985:1 1990:1 1995:1 2000:1 2005:1 2010:1

US: Fed Funds rate, quarterly

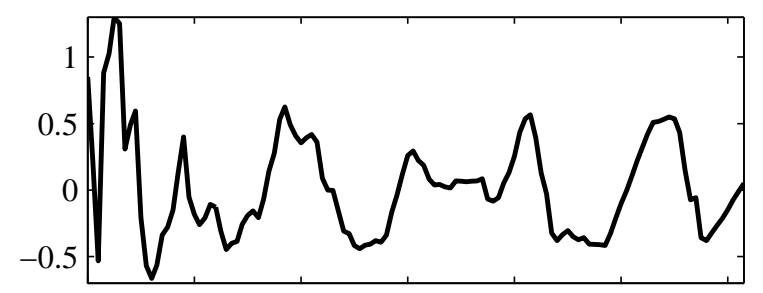

1980:1 1985:1 1990:1 1995:1 2000:1 2005:1 2010:1

US: Average Labour hours

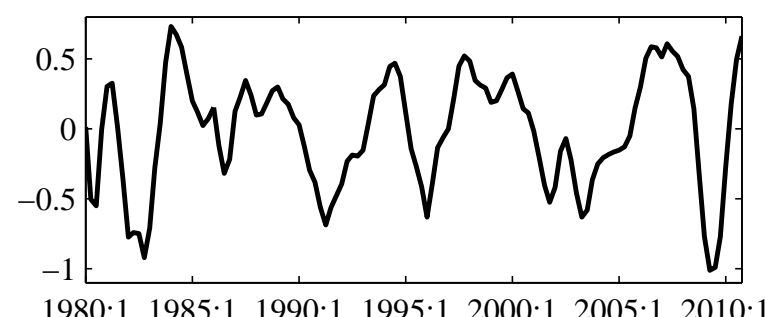


Figure 2: Forecasts versus Actuals for Inflation (DSGE-VAR)

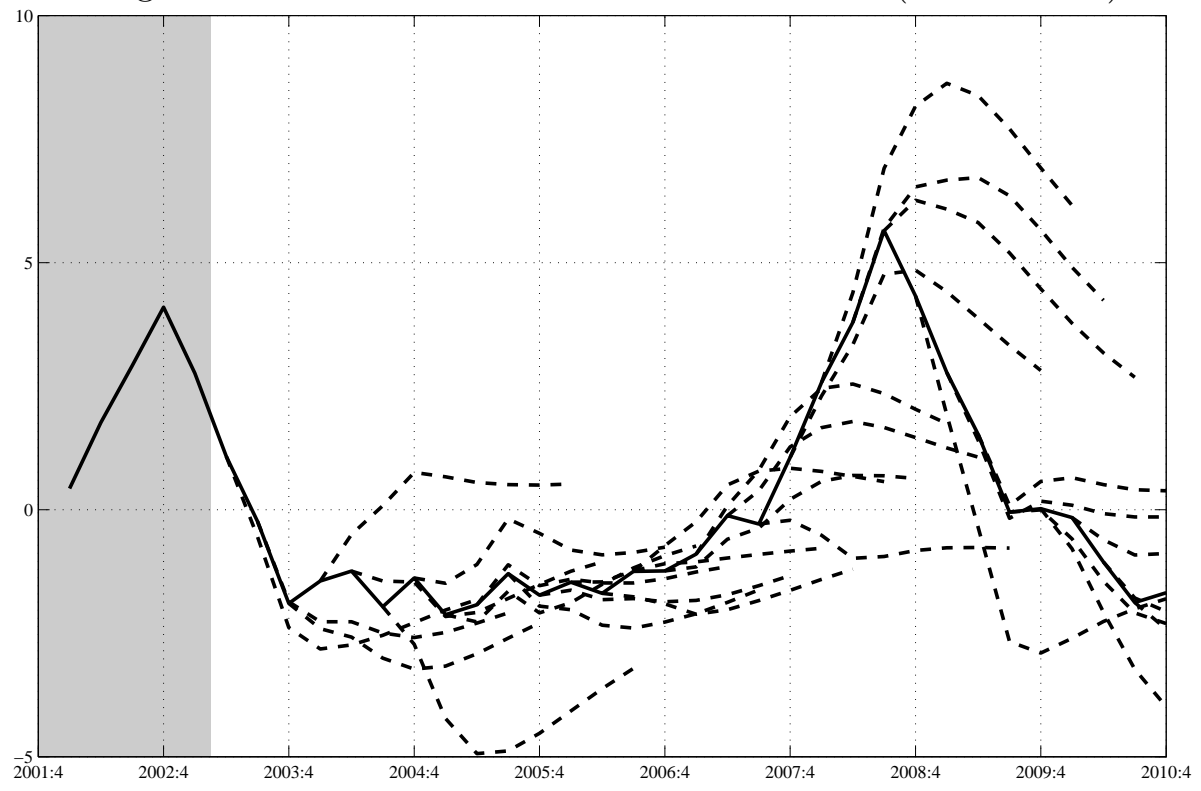

Figure 3: Forecasts versus Actuals for Output (DSGE-VAR)

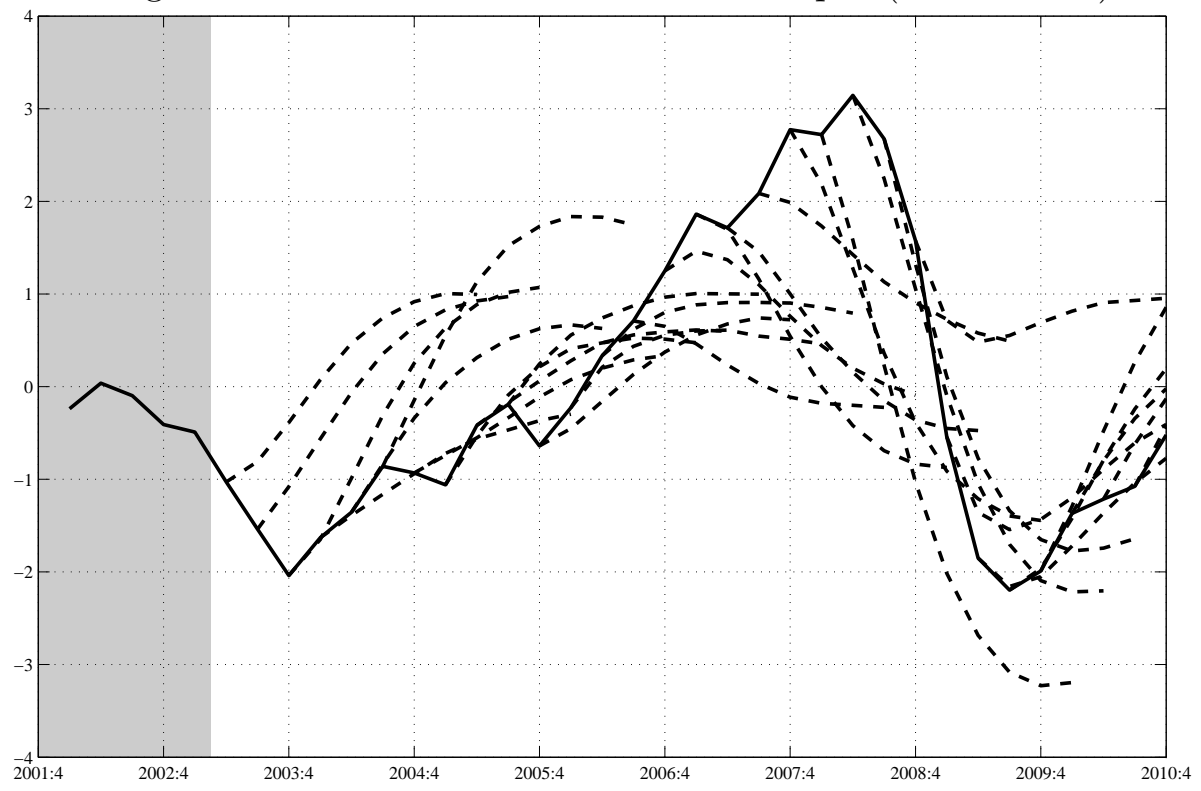


Figure 4: Forecasts versus Actuals for Interest rate (DSGE-VAR)

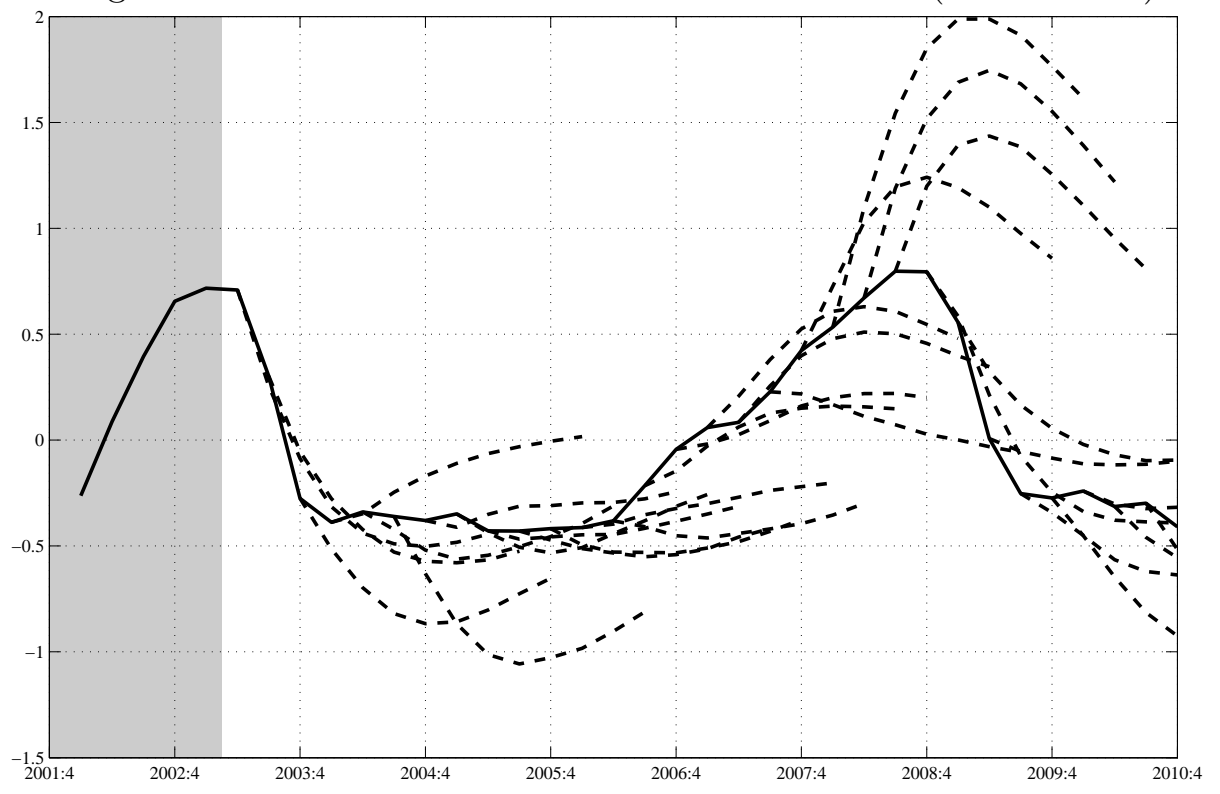

Figure 5: Forecasts versus Actuals for Inflation (BVAR6)

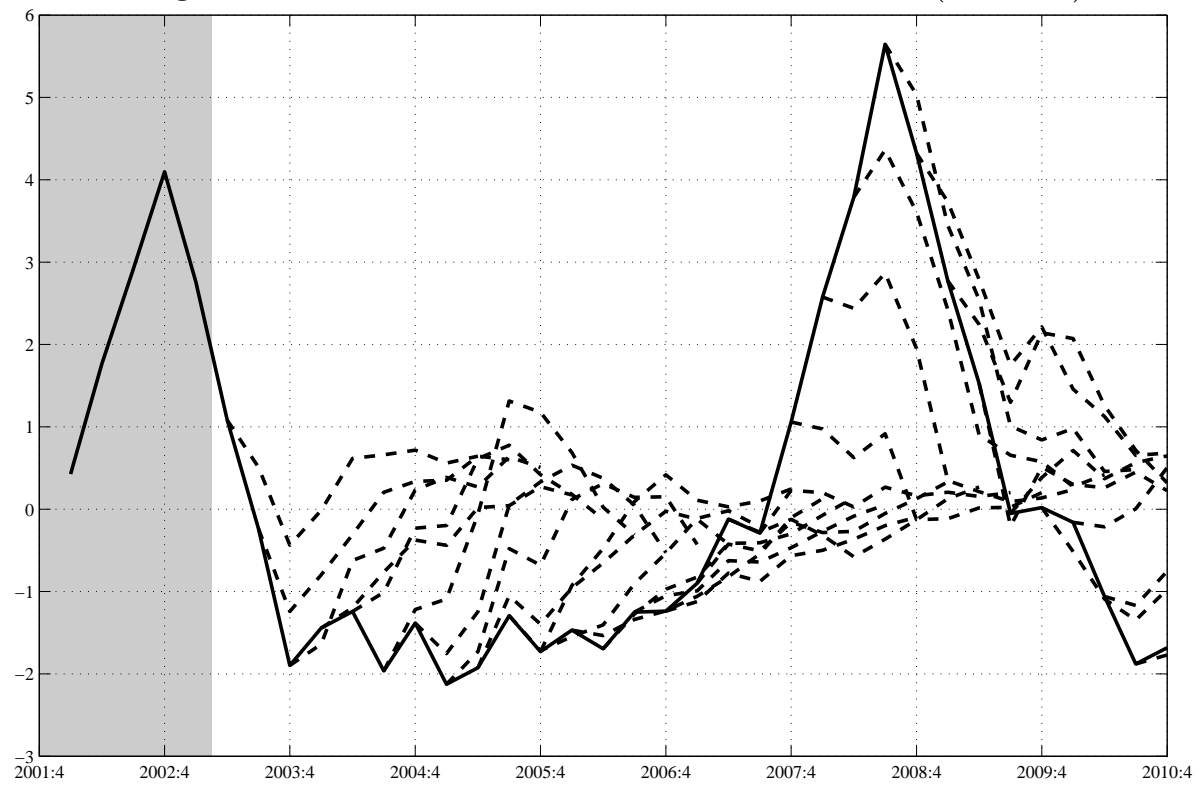


Figure 6: Forecasts versus Actuals for Output (BVAR6)

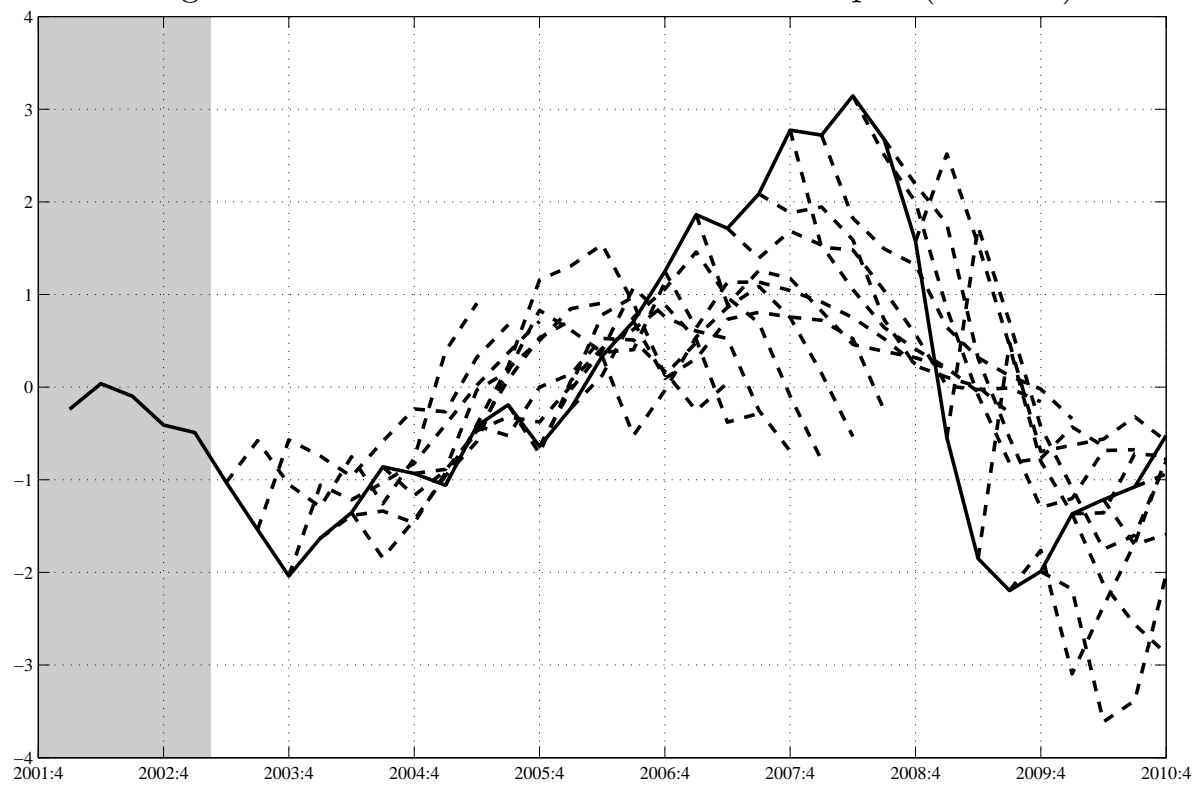

Figure 7: Forecasts versus Actuals for Interest rate (BVAR6)

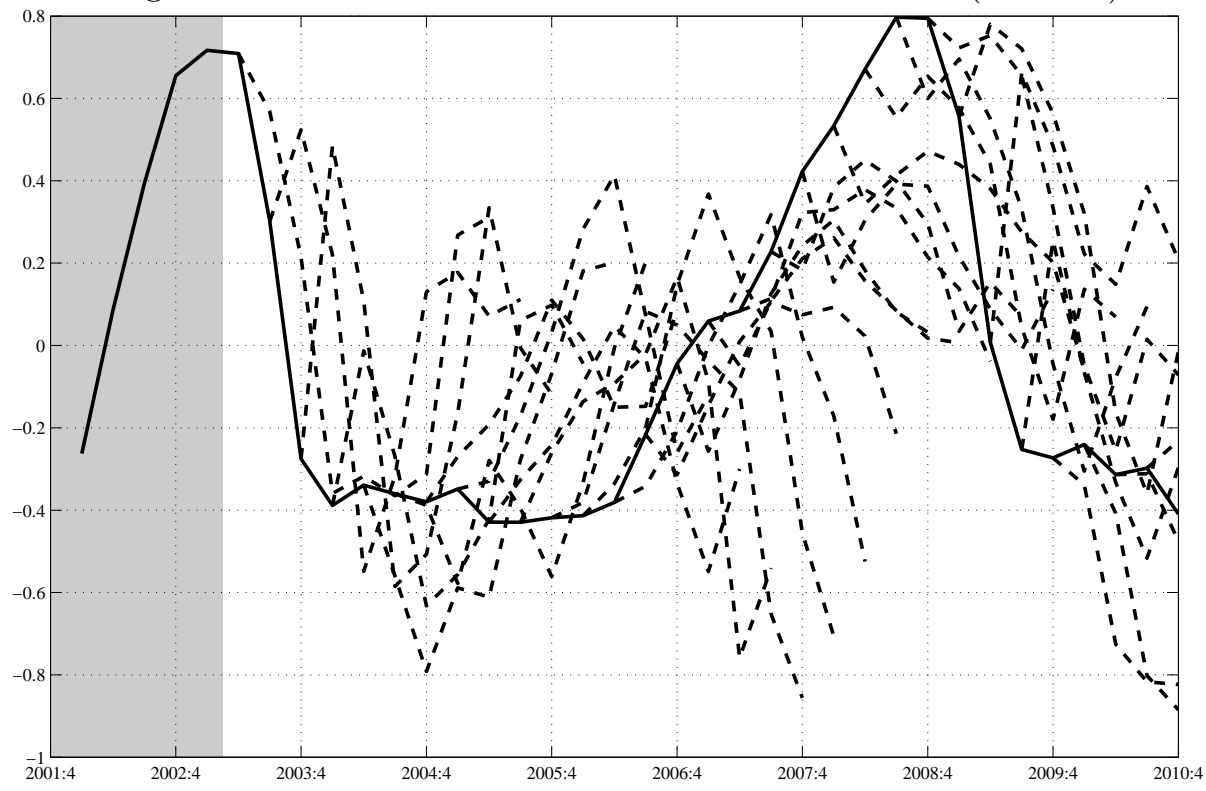

